\title{
Advances and Applications of Clostridium Co-culture Systems in Biotechnology
}

\author{
Yuanfen Du ${ }^{1,2}$, Wei Zou ${ }^{1,2 *}$, Kaizheng Zhang ${ }^{1}$, Guangbin $\mathrm{Ye}^{1}$ and Jiangang Yang ${ }^{1}$ \\ 1 College of Bioengineering, Sichuan University of Science and Engineering, Yibin, China, ${ }^{2}$ Research Laboratory of Baijiu \\ Resource Microorgannisms and Big Data, Sichuan University of Science and Engineering, Yibin, China
}

OPEN ACCESS

Edited by:

Blaz Stres,

University of Ljubljana, Slovenia

Reviewed by:

Stefan Junne,

Technical University of Berlin,

Germany

Aleksander Mahnic,

National Laboratory of Health,

Environment and Food, Slovenia

*Correspondence:

Wei Zou

weizou1985@163.com

Specialty section:

This article was submitted to

Microbiotechnology,

a section of the journal

Frontiers in Microbiology

Received: 08 May 2020

Accepted: 20 October 2020

Published: 16 November 2020

Citation:

Du Y, Zou W, Zhang K, Ye G and Yang J (2020) Advances and Applications of Clostridium

Co-culture Systems in Biotechnology.

Front. Microbiol. 11:560223.

doi: 10.3389/fmicb.2020.560223
Clostridium spp. are important microorganisms that can degrade complex biomasses such as lignocellulose, which is a widespread and renewable natural resource. Coculturing Clostridium spp. and other microorganisms is considered to be a promising strategy for utilizing renewable feed stocks and has been widely used in biotechnology to produce bio-fuels and bio-solvents. In this review, we summarize recent progress on the Clostridium co-culture system, including system unique advantages, composition, products, and interaction mechanisms. In addition, biochemical regulation and genetic modifications used to improve the Clostridium co-culture system are also summarized. Finally, future prospects for Clostridium co-culture systems are discussed in light of recent progress, challenges, and trends.

Keywords: co-culture, Clostridium, hydrogen, butanol, interaction mechanism

\section{INTRODUCTION}

Although axenic cultivation of individual-bacteria has been widely used in fermentation technology, many biological processes require the presence of multiple bacteria in a single system. For instance, co-culturing two or more microorganisms is an important and common fermentation technique that has been extensively applied to several bioprocesses, including food manufacturing (i.e., cheese, yogurt, sauerkraut, sourdough, kefir, salami, whisky, cacao beans, Belgian beer, etc.) (Bader et al., 2010), bio-degradation (i.e., wastewater treatment and biological soil remediation) (Yagi, 2011), and bio-fuel production (Luo et al., 2015). The greatest advantage of co-culture systems is that the combination of the metabolic capacity of two or more microorganisms allows for the utilization of more complex substrates and the production of specific products. In particular, cellulose from sources such as rice straw, wheat straw, corn cobs, corn stalk waste, and sweet sorghum stalk is not easily degraded and utilized. In addition, distillery effluent, crude

Abbreviations: DFE, dark fermentation effluent; CBP, consolidated bioprocessing; OTR, oxygen transfer rate; CFU, colony forming unit; ABE, acetone-butanol-ethanol; FISH, the method of fluorescence in situ hybridization; QPCR, quantitative polymerase chain reaction; RT-qPCR, quantitative reverse-transcription PCR; SEM, the scanning electron microscopy; WLP, the wood-ljungdahl pathway; MCC, microcrystalline cellulose; AQDS, anthraquinone-2, 6-disulfonate; $\mathrm{AH}_{2} \mathrm{QDS}$, anthrahydroquinone-2, 6-disulfonate; ATP, adenosine triphosphate; ADP, adenosine diphosphate; AMP, adenosine monophosphate; $\mathrm{NADH}$, nicotinamide adenine nucleotide; $\mathrm{NAD}^{+}$, nicotinamide adenine dinucleotide; $\mathrm{COD}$, chemical oxygen demand; 1,3-PD, 1,3-propanediol; $\mathrm{CH}_{4}$, methane; $\mathrm{CO}$, carbon monooxide; $\mathrm{CO}_{2}$, carbon-dioxide; $\mathrm{H}_{2}$, hydrogen; TS, total solid; CSTBR, continuous stirred tank bioreactor; $L d h$, lactate dehydrogenase; Pta, phosphotransacetylase; DMAP, dynamic microwave-assisted alkali pretreatment; APBR, an up-flow anaerobic packed-bed reactor; CFS, continuous fermentation system; S-HF/MBRs, two submerged hollow-fiber membrane bioreactors; CSTR, continuous stirredtank reactors. 
glycerol, apple pomace, banana agro-waste, cassava starch, lactate, gelatin, yeast waste, various other carbohydrates, carbon monoxide and syngas can also be processed using these systems (Charubin et al., 2018). Inexpensive, renewable biomass and agricultural wastes from abundant renewable resources can be converted into bio-fuels and bio-solvents by pure bacterial cultures or by co-cultures of microorganisms. In co-culture systems, microorganisms stably coexist by interacting with each other and provide various functional factors or materials more effectively than single cultures, due to the synergistic involvement of the metabolic pathways of all involved strains (Wu et al., 2016).

Clostridia are Gram-positive, anaerobic or obligate anaerobic bacteria that are among a metabolically diverse group that includes cellulolytic, acetogenic, chain-elongating and solventogenic bacteria (Salimi et al., 2010; Charubin et al., 2018). Clostridia perform diverse metabolic functions, including the conversion of starch, protein, and purines into organic acids (i.e., acetic, butyric, and caproic acids), alcohols, $\mathrm{CO}_{2}$, and hydrogen (Zou et al., 2018b). Because of their broad and flexible metabolic capabilities, Clostridium species are included in many microbial co-culture ecosystems, which we will refer to in this review as "Clostridium co-culture systems."

Typically, Clostridium co-culture systems are used to produce bio-fuels such as hydrogen and $\mathrm{CH}_{4}$, solvents, and organic acids (Jiang et al., 2019). Because cellulosic materials are commonly found in nature ( $\mathrm{Lu}$ et al., 2017), the specific metabolic capacities of cellulolytic strains and producers in co-culture systems have attracted significant attention and offered many long-term prospects for development. In this review, we summarize recent progress on Clostridium co-culture systems, including their advantages, products, composition, interaction mechanisms, and regulation. Significant attention is paid to describing the regulation strategies based on an understanding of the interactions to improve the stability and fermentation performance of the Clostridium co-culture systems that have been used in large-scale bioprocesses and optimized for biotechnology applications.

\section{ADVANTAGES OF Clostridium CO-CULTURE SYSTEMS}

Compared to a mono-culture, there are many unique and essential advantages of the Clostridium co-culture systems. Firstly, co-culturing Clostridium spp. and other microorganisms makes it possible to utilize more extensive and complex substrates including the abundant renewable resources of lignocellulosic biomass in nature such as cedar (Rabemanolontsoa et al., 2016), aspen (Xu and Tschirner, 2014), agave (Oliva-Rodríguez et al., 2019), cassava (Qi et al., 2018), miscanthus biomass (Raut et al., 2019), switchgrass (Flythe et al., 2015), salix (Pang et al., 2018b), and many types of agricultural waste such as crop straw, fruit residue, etc. Food waste (Tavabe et al., 2010) and industrial waste including biodiesel waste (crude glycerol) and yeast waste can also be used.

Secondly, Clostridium co-culture systems can increase the efficiency of substrate utilization. For example, in the co-culture of C. thermocellum JN4 and Thermoanaerobacterium thermosaccharolyticum GD17, the cellulase complex of C. thermocellum JN4 can hydrolyze xylan to xylobiose and xylose but cannot utilize xylobiose or xylose, but T. thermosaccharolyticum GD17 can utilize these substrates to produce $\mathrm{H}_{2}$, organic acids and ethanol (Liu et al., 2008; Pang et al., 2018a,b). A co-culture system will also increase the substrate utilization rate when both bacteria can use the substrate to produce the target product (Pachapur et al., 2015a).

Thirdly, the Clostridium co-culture system can improve product yield. Hydrogen production by the co-culture of Rhodobacter sphaeroides and C. butyricum was enhanced by $160 \%$ compared with that by the mono-culture of C. butyricum (Zhu et al., 2001). In the co-culture of C. beijerinckii and Geobacter metallireducens, G. metallireducens utilized AQDS as an electron acceptor, regenerating $\mathrm{AH}_{2} \mathrm{QDS}$, which caused changes in the intracellular $\mathrm{NADH} / \mathrm{NAD}^{+}$ratio and a metabolic shift from the butyric acid pathway to the acetic acid pathway. This enhanced the hydrogen molar yield, the hydrogen production rate, and the extent of xylose utilization by C. beijerinckii (Zhang et al., 2012).

The fourth advantage is the improvement of system robustness. On the one hand, co-cultures with facultative anaerobic or aerobic bacteria will consume oxygen during the co-culture and provide anaerobic conditions for Clostridium (Zuroff et al., 2013; Wushke et al., 2015; Mai et al., 2016; Ebrahimi et al., 2019; Oliva-Rodríguez et al., 2019). On the other hand, metabolites that inhibit Clostridium growth may be removed by co-culture partners. For example, formate, which inhibits the growth of $C$. cellulolyticum, could be consumed by the hydrogen-evolving bacterium Citrobacter amalonaticus and transformed into hydrogen (Zhang et al., 2016b). Methanogen 166 converted accumulated $\mathrm{H}_{2}$ that was produced by C. kluyveri $\mathrm{H} 068$ into methane, thereby eliminating the hydrogen-mediated feedback inhibition that normally constrains C. kluyveri H068 and thus enhancing caproic acid production (Yan and Dong, 2018).

A fifth advantage is that a Clostridium co-culture system can elongate the product synthesis chain. In addition to the use of complex organic carbohydrates, the Clostridium coculture system can also use simple inorganic carbon, such as carbon monoxide and carbon dioxide, to synthesize polycarbonic organic acids or alcohols. For example, acetogenic Clostridia can convert $\mathrm{CO}, \mathrm{CO}_{2}$ and syngas to ethanol and acetate that can be utilized by chain-elongating Clostridia or solventogenic Clostridia to produce medium-chain fatty acids (e.g., butyrate and caproate) and higher alcohols (e.g., butanol and hexanol and even octanol) in the acetogenic Clostridium co-culture (Diender et al., 2016; Richter et al., 2016; Youn, 2017; Li and Henson, 2019).

The sixth advantage is the scalability of Clostridium co-culture systems. In addition to laboratory-scale anaerobic bottle or shake bottle studies, larger fermentation tanks or bioreactors have been used in the Clostridium co-culture system and have been proved to have significant effects, like eliminating substrate inhibition (Pachapur et al., 2016a), increasing product yield (Zhang et al., 2012; Salimi and Mahadevan, 2013; Luo et al., 2017; Morsy, 2017; Kim et al., 2018; Cheng et al., 2019), showing good 
stability (Masset et al., 2012) and continuous and stable product generation (Barca et al., 2016; Wu et al., 2016).

In addition, a Clostridium co-culture system can reduce the cost of fermentation and simplify the process. On the one hand, the Clostridium co-culture system can utilize cheaper renewable substrates. On the other hand, co-culturing Clostridium with Bacillus or other facultative anaerobic or aerobic bacteria that are able to consume oxygen, providing an anaerobic environment for Clostridium, precludes the need for expensive reductants or anaerobic operating conditions or equipment (Mai et al., 2016; Srivastava et al., 2018; Ebrahimi et al., 2019; Oliva-Rodríguez et al., 2019). And growth needs can also be met without the addition of exogenous nutrients (Mori, 1990). In some cases, lignocellulose can be directly converted into products without the need for pretreatment (Islam et al., 2017; Sander et al., 2017). However, there are still some issues and challenges associated with the co-cultures, such as instability, toxic byproducts of the other species, greater efforts required for control, and a lack of established technology for large-scale industrial application.

\section{MICROBIAL COMPOSITION AND PRODUCTS OF Clostridium CO-CULTURE SYSTEMS}

\section{Co-culture Systems of Cellulolytic Clostridia and Solventogenic Clostridia}

Co-culturing cellulolytic Clostridium and solventogenic Clostridium species not only results in the degradation of complex lignocellulosic substrates, but can also produce high-value solvents and green hydrogen energy from cheap renewable resources (Table 1). In the co-culture system, the most extensively used cellulolytic Clostridia are C. thermocellum, C. celevecrescens, C. cellulovorans, and C. termitidis.

In the early phase, $\mathrm{Ng}$ and his colleagues co-cultured C. thermocellum strain LQRI, which can hydrolyze alpha cellulose and hemicelluloses to produce ethanol and acetate, with C. thermohydrosulfuricum strain 39E, which can ferment glucose, cellobiose, and xylose to produce ethanol and acetate, and fermented a variety of cellulosic substrates. The ethanol yield observed was twofold higher than in C. thermocellum mono-culture fermentations ( $\mathrm{Ng}$ et al., 1981). At the same time, a higher ethanol yield was obtained by a co-culture of C. thermohydrosulfuricum YM3 and C. thermocellum YM4, which was very stable and degraded avicel more rapidly than did strain YM4 mono-culture. Moreover, strain YM3 could replace yeast extract in supporting the growth of strain YM4 to produce a high ethanol yield (Mori, 1990). In addition, C. thermosacchrolyticum and C. thermolacticum were used in co-culture with $C$. thermocellum to produce ethanol (Saddler and Chan, 1984; Xu and Tschirner, 2011). Some agricultural wastes can also be directly converted to ethanol. In the co-culture system of C. thermocellum CT2 and C. thermosaccharolyticum HG8 fermented on alkali-treated banana-agro waste (leaves), C. thermosaccharolyticum utilized the xylose and pentose sugars formed during hemicellulose degradation by $C$. thermocellum, which are unable to be utilized by $C$. thermocellum. The co-culture showed higher ethanol production, improved cellulose degradation, and enhanced reducing sugars utilization and remained active even at substrate concentrations up to $100 \mathrm{~g} / \mathrm{L}$ (obtaining a maximum ethanol yield of $22 \mathrm{~g} / \mathrm{L}$ ) (Harish et al., 2010).

Clostridium thermocellum can also be utilized to co-culture with C. beijerinckii or C. acetobutylicum. Solventogenic Clostridia use saccharides produced by $C$. thermocellum hydrolysis of lignocellulosic substrate for acetone-butanol-ethanol (ABE) fermentation ( $\mathrm{Yu}$ et al., 1985; Lin et al., 2013; Wen et al., 2014b; Flythe et al., 2015). Wen and colleagues utilized alkali-extracted corn cobs as substrate and obtained $19.9 \mathrm{~g} / \mathrm{L}$ $\mathrm{ABE}$ in the co-culture of C. thermocellum ATCC27405 and C. beijerinckii NCIMB8052 in a one-pot reaction (Wen et al., 2014b). In addition to the co-culture thermophilic cellulolytic Clostridia and solventogenic Clostridia for ABE fermentation, mesophilic cellulolytic Clostridia (e.g., C. celevecrescens N32, C. cellulovorans 743B) are also applied in co-culture for ABE fermentation (Wen et al., 2014a; Wang et al., 2015). Co-culture of C. cellulovorans 743B and C. beijerinckii NCIMB8052 degraded $68.6 \mathrm{~g} / \mathrm{L}$ alkali-extracted, deshelled corn cobs and produced $11.8 \mathrm{~g} / \mathrm{L}$ of solvents under optimized conditions (Wen et al., 2014a) and also demonstrated the ability of C. beijerinckii NCIMB8052 to utilize mandarin orange wastes in an isopropanol-butanol-ethanol fermentation (Tomita et al., 2019).

Clostridium thermoaceticum has also been co-cultured with C. thermocellum to produce a large amount of acetic acid from lignocellulose. Rabemanolontsoa and colleagues first reported the simultaneous conversion of cellulose-, hemicellulose-, ligninderived compounds from biomass derived from hot-compressed water treatment of Japanese cedar into acetic acid. They employed a co-culture of C. thermocellum ATCC27405 and C. thermoaceticum ATCC39073, which can ferment the obtained products, together with other low-molecular-weight products such as monosaccharides, decomposed products, and organic acids, into acetic acid (Rabemanolontsoa et al., 2016). They found that non-sparged $\mathrm{N}_{2}$ and sparged $\mathrm{CO}_{2}$ promoted growth and acetic acid production of the co-culture C. thermocellum ATCC27405 and C. thermoaceticum ATCC39073, while sparged $\mathrm{N}_{2}$ inhibited both microorganisms, and produced $10.3 \mathrm{~g} / \mathrm{L}$ of acetic acid from cellobiose under $\mathrm{CO}_{2}$ sparging.

In addition to co-culturing cellulolytic Clostridium and solventogenic Clostridium to produce solvents, hydrogen production has also been explored. C. thermocellum DSM1237, possessing the capacity to hydrolyze cellulose to produce hydrogen, was co-cultured with C. thermopalmarium DSM5974, which can produce hydrogen but cannot hydrolyze cellulose, and the co-culture produced nearly double the hydrogen production of C. thermocellum DSM1237 mono-cultures (Geng et al., 2010). At the same time, the co-culture of thermophilic C. thermosaccharolyticum DSM869 with C. thermocellum DSM7072, which can degrade cellulose and hemicellulose from cellulosic materials to produce soluble sugars, hydrogen, and acetic acid, also produced hydrogen from cornstalk waste ( $\mathrm{Li}$ and Liu, 2012; Li et al., 
TABLE 1 | Overview of Clostridium co-cultures of cellulolytic Clostridia and solventogenic Clostridia in biotechnology applications.

\begin{tabular}{|c|c|c|c|c|c|}
\hline Applied micro-organisms & Inoculumratios/size & Substrate & Product/process & yield & References \\
\hline $\begin{array}{l}\text { C. thermocellum LQRI, } \\
\text { C. thermohydrosulfuricum39E }\end{array}$ & $1: 1$ & $\begin{array}{l}\text { Cellulosic } \\
\text { Substrates }\end{array}$ & Ethanol & $\begin{array}{l}1.8 \mathrm{~mol} / \mathrm{mol} \text { a hydroglucose } \\
\text { unit in cellulose }\end{array}$ & Ng et al., 1981 \\
\hline $\begin{array}{l}\text { C. thermocellum YM4, } \\
\text { C. thermohydrosulfuricum YM3 }\end{array}$ & $1: 1$ & Avicel & Ethanol & $\begin{array}{l}1.96 \mathrm{~mol} / \mathrm{mol} \text { of a } \\
\text { hydroglucose unit in } \\
\text { cellobiose }\end{array}$ & Mori, 1990 \\
\hline $\begin{array}{l}\text { C. thermocellum, } \\
\text { C. thermosaccharolyticum, } \\
\text { C. thermohydrosulphuricurn }\end{array}$ & $\begin{array}{l}\text { The inoculum of all the } \\
\text { strain were } 5 \%(\mathrm{v} / \mathrm{v}) \\
\text { after the same culture } \\
\text { time }\end{array}$ & $\begin{array}{l}\text { Lignocellulosic } \\
\text { substrates }\end{array}$ & Ethanol & $2.9 \mathrm{~g} / \mathrm{L}$ & $\begin{array}{l}\text { Saddler and Chan, } \\
1984\end{array}$ \\
\hline $\begin{array}{l}\text { C. thermocellum ATCC } 27405 \text {, } \\
\text { C. thermolacticum ATCC } 43739\end{array}$ & $1: 1$ & Xylose & Ethanol & $4.539 \mathrm{~g} / \mathrm{L}$ & Xu and Tschirner, 2011 \\
\hline $\begin{array}{l}\text { C. thermocellum CT2, } \\
\text { C. thermosaccharolyticum HG8 }\end{array}$ & $\begin{array}{l}\text { All are } 5 \%(\mathrm{v} / \mathrm{v}) \\
\text { inoculums after } 24 \mathrm{~h} \text { of } \\
\text { culture }\end{array}$ & Banana agro-waste & Ethanol & $22 \mathrm{~g} / \mathrm{L}$ & Harish et al., 2010 \\
\hline $\begin{array}{l}\text { C. thermocellum ATCC } 27405 \text {, } \\
\text { C. thermolacticum ATCC } 43739\end{array}$ & $1: 1$ & Cellobiose & Ethanol & $4.8 \mathrm{~g} / \mathrm{L}$ & Xu and Tschirner, 2014 \\
\hline $\begin{array}{l}\text { C. thermocellum NRCC2688, } \\
\text { C. acetobutylicum ATCC } 824\end{array}$ & $\begin{array}{l}\text { The inoculum of all the } \\
\text { strain were } 5 \%(v / v) \\
\text { after } 3 \text { days of culture }\end{array}$ & $\begin{array}{l}\text { Lignocellulosic } \\
\text { substrates }\end{array}$ & Butanol & $0.3 \mathrm{~g} / \mathrm{L}$ & Yu et al., 1985 \\
\hline $\begin{array}{l}\text { C. thermocellum ATCC } 27405 \text {, } \\
\text { C. saccharoperbutylacetonicum } \\
\text { strain N1-4 }\end{array}$ & $1: 1$ & Crystalline cellulose & Butanol & $7.9 \mathrm{~g} / \mathrm{L}$ & Nakayama et al., 2011 \\
\hline $\begin{array}{l}\text { C. cellulolyticum ATCC35317, } \\
\text { C. acetobutylicum ATCC824 }\end{array}$ & $1: 1$ & Cellulose & Butanol & $350 \mathrm{mg} / \mathrm{L}$ & $\begin{array}{l}\text { Salimi and Mahadevan, } \\
2013\end{array}$ \\
\hline $\begin{array}{l}\text { C. thermocellum ATCC } 27405 \text {, } \\
\text { C. beijerinckii NCIMB8052 }\end{array}$ & Unavailable & Corncob & Butanol & $8.75 \mathrm{~g} / \mathrm{L}$ & Lin et al., 2013 \\
\hline $\begin{array}{l}\text { C. thermocellum ATCC27405, } \\
\text { C. beijerinckii NCIMB8052 }\end{array}$ & $\begin{array}{l}\text { The inoculums of strain } \\
\text { ATCC27405 was 10\% } \\
(\mathrm{v} / \mathrm{v}) \text {, and NCIMB8052 } \\
\text { was } 1 \%(\mathrm{~V} / \mathrm{v})\end{array}$ & $\begin{array}{l}\text { Alkali extracted } \\
\text { corn cobs }\end{array}$ & $\mathrm{ABE}$ & $\begin{array}{l}\text { ABE } 19.9 \mathrm{~g} / \mathrm{L} \text { (acetone } \\
3.96 \text {, butanol } 10.9 \text { and } \\
\text { ethanol } 5.04 \mathrm{~g} / \mathrm{L} \text { ) }\end{array}$ & Wen et al., 2014b \\
\hline $\begin{array}{l}\text { C. cellulovorans } 743 \mathrm{~B} \text {, } \\
\text { C. beijerinckii NCIMB8052 }\end{array}$ & $10: 1(v / v)$ & $\begin{array}{l}\text { Deshelled corn } \\
\text { cobs }\end{array}$ & $\mathrm{ABE}$ & $\begin{array}{l}11.8 \mathrm{~g} / \mathrm{L} \text { solvents }(2.64 \mathrm{~g} / \mathrm{L} \\
\text { acetone, } 8.30 \mathrm{~g} / \mathrm{L} \text { butanol } \\
\text { and } 0.87 \mathrm{~g} / \mathrm{L} \text { ethanol) }\end{array}$ & Wen et al., 2014a \\
\hline $\begin{array}{l}\text { C. thermocellum NBRC103400, } \\
\text { C. saccharoperbutylacetonicum } \\
\text { N1-4 }\end{array}$ & $1: 1$ & Rice straw & Butanol & $6.9 \mathrm{~g} / \mathrm{L}$ & Kiyoshi et al., 2015 \\
\hline $\begin{array}{l}\text { C. celevecrescens N3-2, } \\
\text { C. acetobutylicum ATCC824 }\end{array}$ & $\begin{array}{l}\text { The inoculums of both } \\
\text { strains were } 2 \mathrm{~mL}\end{array}$ & Cellulose & Butanol & $3.73 \mathrm{~g} / \mathrm{L}$ & Wang et al., 2015 \\
\hline $\begin{array}{l}\text { C. thermocellum ATCC27405, } \\
\text { C. saccharoperbutylacetonicum } \\
\text { ATCC27021 N1-4 }\end{array}$ & $1: 1$ & Switchgrass & Solvents & $207 \mathrm{mg}$ & Elia et al., 2016 \\
\hline $\begin{array}{l}\text { C. cellulovorans ATCC35296, } \\
\text { C. beijerinckii NCIMB8052 }\end{array}$ & Unavailable & $\begin{array}{l}\text { Mandarin orange } \\
\text { wastes }\end{array}$ & Butanol & $\begin{array}{l}0.046 \mathrm{~g} / \mathrm{g} \text { dried strained } \\
\text { lees }\end{array}$ & Tomita et al., 2019 \\
\hline $\begin{array}{l}\text { C. thermocellum ATCC } 27405 \text {, } \\
\text { C. thermoaceticum ATCC39073 }\end{array}$ & $1: 1$ & Japanese cedar & Acetic acid & 897 mg/L & $\begin{array}{l}\text { Rabemanolontsoa } \\
\text { et al., } 2016\end{array}$ \\
\hline $\begin{array}{l}\text { C. thermocellum ATCC } 27405 \text {, } \\
\text { C. thermoaceticum ATCC39073 }\end{array}$ & $1: 1$ & Glucose & Acetic acid & $14.8 \mathrm{~g} / \mathrm{L}$ & $\begin{array}{l}\text { Rabemanolontsoa } \\
\text { et al., } 2017\end{array}$ \\
\hline $\begin{array}{l}\text { C. thermocellum ATCC } 27405 \text {, } \\
\text { C. thermopalmarium DSM5974 }\end{array}$ & 1:0.05 & Cellulose & Hydrogen & $1387 \mathrm{ml} / \mathrm{L}$ & Geng et al., 2010 \\
\hline $\begin{array}{l}\text { C. thermocellum DSM7072, } \\
\text { C. thermosaccharolyticum } \\
\text { DSM869 }\end{array}$ & $1: 0.25$ & Cornstalk waste & Hydrogen & $68.2 \mathrm{~mL} / \mathrm{g}$ cornstalk & Li and Liu, 2012 \\
\hline $\begin{array}{l}\text { C. thermocellum DSM7072, } \\
\text { C. thermosaccharolyticum } \\
\text { DSM869 }\end{array}$ & $4: 1$ & Cornstalk & Hydrogen & $105.61 \mathrm{~mL} / \mathrm{g}$ cornstalk & Li et al., 2014 \\
\hline $\begin{array}{l}\text { C. thermocellum ATCC } 27405 \text {, } \\
\text { C. beijerinckii ATCC51743 }\end{array}$ & $1: 1$ & Switchgrass & Gas & $680 \mathrm{~mL}$ gas & Flythe et al., 2015 \\
\hline
\end{tabular}


TABLE 1 | Continued

\begin{tabular}{|c|c|c|c|c|c|}
\hline Applied micro-organisms & Inoculumratios/size & Substrate & Product/process & yield & References \\
\hline $\begin{array}{l}\text { C. thermocellum DSM7072, } \\
\text { C. thermosaccharolyticum } \\
\text { DSM572 }\end{array}$ & $1: 1$ & $\begin{array}{l}\text { Sweet sorghum } \\
\text { stalk }\end{array}$ & Hydrogen & $5.1 \mathrm{mmol} / \mathrm{g}$-substrate & Islam et al., 2017 \\
\hline $\begin{array}{l}\text { C. termitidis ATCC51846, } \\
\text { C. beijerinckii DSM1820 }\end{array}$ & $1: 1$ & Cellulose & Hydrogen & $\begin{array}{l}1.92 \mathrm{~mol} \\
\text { hydrogen/molhexose } \\
\text { equivalent } \\
\text { added }\end{array}$ & $\begin{array}{l}\text { Gomez-Flores et al., } \\
2017\end{array}$ \\
\hline $\begin{array}{l}\text { C. cellulovorans ATCC35296, } \\
\text { C. acetobutylicum CDBB-B1496 }\end{array}$ & $5: 3$ & $\begin{array}{l}\text { Lignocellulosic } \\
\text { substrates }\end{array}$ & Hydrogen & $128 \mathrm{~mL} / \mathrm{L}$ & $\begin{array}{l}\text { Valdez-Vazquez et al., } \\
2019\end{array}$ \\
\hline
\end{tabular}

2014). Further, C. thermosaccharolyticum DSM572, which can utilize soluble sugars to produce hydrogen, acetic acid, and butyric acid, co-cultured with $C$. thermocellum DSM7072 produced $5.1 \mathrm{mmol} \mathrm{H}_{2} / \mathrm{g}$ substrate, $1.27 \mathrm{~g} / \mathrm{L}$ acetic acid, and $1.05 \mathrm{~g} / \mathrm{L}$ butyric acid via thermophilic fermentation of sweet sorghum stalk (Islam et al., 2017). Moreover, mesophilic cellulolytic Clostridia have also been employed to produce hydrogen in a Clostridium co-culture system. The co-culture of C. cellulovorans ATCC35296 and C. acetobutylicum CDBB-B-1496 achieved a 2- to 3fold improvement in hydrogen production in comparison with C. acetobutylicum CDBB-B-1496 mono-cultures from lignocellulosic substrates (Valdez-Vazquez et al., 2019). In addition, co-culturing C. termitidis ATCC51846, which can degrade cellulose to produce hydrogen, and C. beijerinckii DSM1820 achieved a high hydrogen yield of $1.92 \mathrm{~mol} / \mathrm{mol}$ hexose equivalent ${ }_{\text {added }}$ compared to $1.45 \mathrm{~mol} / \mathrm{mol}$ hexose equivalent $\mathrm{added}_{\text {in }}$ the mono-culture from cellulose (Gomez-Flores et al., 2017).

\section{Co-culture Systems of Celluloytic Clostridia With Other Microorganisms}

Co-culturing cellulolytic Clostridia with other microorganisms has often been employed to produce hydrogen and ethanol (Table 2). C. thermocellum, C. cellulovorans, C. cellulolyticum, and C. phytofermentans were commonly used in co-culture. Different substrate utilizations were investigated in the co-culture system of C. thermocellum ATCC27405 and Thermoanaerobacterium saccharolyticum DSM571 to produce ethanol (Pang et al., 2018a,b). Among the co-cultures, Thermoanaerobacterium saccharolyticum DSM571 could utilize pentose and hexose, which were degraded and not used by $C$. thermocellum ATCC27405 to produce ethanol, but which could increase substrate utilization and product yield. In addition, the coculture of C. thermocellum DSM1237 and Caldibacillus debilis GB1 achieved aerotolerant ethanogenic bio-fuel production of $5.5 \mathrm{mmol} / \mathrm{L}$ cell culture from cellulose (Wushke et al., 2015). At the same time, co-culturing the cellulolytic mesophile C. phytofermentans and Candida molischiana or S. cerevisiae cdt-1 achieved a more stable obligate mutualism for consortiamediated lignocellulosic ethanol production by controlling the volumetric transport rate of oxygen. In the co-culture, both yeasts could provide respiratory protection to the obligate anaerobic C. phytofermentans and converted soluble carbohydrates released by cellulose hydrolysis to ethanol (Zuroff et al., 2013).

In addition to producing ethanol via lignocellulose degradation, the co-culture of two thermophilic, anaerobic bacteria, C. thermocellum JN4 and Thermoanaerobacterium thermosaccharolyticum GD17, that were isolated from rotten wheat straw increased hydrogen production by about twofold compared to C. thermocellum JN4 mono-culture (Liu et al., 2008). In addition, mesophilic cellulolytic C. cellulolyticum DSM5812 was co-cultured with non-cellulolytic hydrogenfermenting bacteria to produce hydrogen from corn stover. Citrobacter amalonaticus Y19 utilized glucose and xylose released by C. cellulolyticum hydrolysis of corn stover to produce hydrogen and consumed formate, which inhibits the growth of C. cellulolyticum and was transformed into hydrogen (Zhang et al., 2016b). Although cellulolytic Clostridia may play an economically relevant role in hydrogen production in anaerobic digesters from a high percentage of cellulosic materials, fermentative hydrogen yields are low on account of electrons lost during the obligate excretion of organic acids and alcohols. Jiao and colleagues artificially established a co-culture containing C. cellulolyticum $\mathrm{H} 10$ and the photosynthetic purple bacterium Rhodopseudomonas palustris CGA009 that can consume fermentation products such as acetic acid and butyric acid to produce $\mathrm{H}_{2}$ via nitrogenase during nitrogen fixation. In this co-culture, C. cellulolyticum could degrade all added cellulose $(5.5 \mathrm{~g} / \mathrm{L})$ at a higher growth rate, and the total hydrogen production was 1.6 times higher than that produced by the C. cellulolyticum mono-culture (Jiao et al., 2012). And the co-culture system of C. cellulovorans $743 \mathrm{~B}$ and Rhodopseudomonas palustris CGA009 obtained a $\mathrm{H}_{2}$ production rate of $12.2 \pm 1.2 \mathrm{~mL} /$ day at optimized cellulose concentration (Lu and Lee, 2015).

The Clostridium co-culture system can also produce methane in addition to producing hydrogen and solvents, in particular the co-culture of cellulolytic Clostridia and methanogens including Methanosarcina barkeri Fusaro, Methanosarcina mazei, and Methanothermobacter thermautotrophicus (Sasaki et al., 2012; Lu et al., 2017). Lu et al. (2017) established two co-culture models combining C. cellulovorans 743B with Methanosarcina barkeri Fusaro or Methanosarcina mazei, that could directly convert cellulose into methane and obtained a $\mathrm{CH}_{4}$ yield of $0.87 \pm 0.02 \mathrm{~mol} / \mathrm{mol}$ glucose equivalent using cellulose in the cocultures in which C. cellulovorans degraded cellulose to hydrogen, 
TABLE 2 | Overview of Clostridium co-cultures of cellulolytic Clostridia in biotechnology applications.

\begin{tabular}{|c|c|c|c|c|c|}
\hline Applied micro-organisms & Inoculum ratios/size & Substrate & Product/process & Yield/production rates & References \\
\hline $\begin{array}{l}\text { C. thermocellum ATCC35609, } \\
\text { Thermoanaerobacter } \\
\text { pseudethanolicus strain 39E }\end{array}$ & $1: 1$ & Cellulose & Ethanol & $>60 \mathrm{mM}$ & Qiang et al., 2011 \\
\hline $\begin{array}{l}\text { C. thermocellum, } \\
\text { Thermoanaerobacterium } \\
\text { saccharolyticum }\end{array}$ & $1: 1$ & Avicel & Ethanol & $38 \mathrm{~g} / \mathrm{L}$ & Argyros et al., 2011 \\
\hline $\begin{array}{l}\text { C. phytofermentans, } \\
\text { Saccharomyces cerevisiae cdt-1 }\end{array}$ & Unavailable & Cellulose & Ethanol & $22 \mathrm{~g} / \mathrm{L}$ & Zuroff et al., 2013 \\
\hline $\begin{array}{l}\text { C. thermocellum DSM1237, } \\
\text { Caldibacillus debilis GB1 }\end{array}$ & $1: 1$ & Cellulose & Ethanol & $4.2 \mathrm{mM}$ & Wushke et al., 2015 \\
\hline $\begin{array}{l}\text { C. thermocellum DSM1237, } \\
\text { Caldibacillus debilis GB1 }\end{array}$ & $1: 1$ & Cellulose & Ethanol & $6.3 \mathrm{mmol} / \mathrm{L}$ & Wushke et al., 2015 \\
\hline $\begin{array}{l}\text { C. thermocellum ATCC } 27405 \text {, } \\
\text { Thermoanaerobacterium } \\
\text { thermosaccharolyticum DSM571 }\end{array}$ & $1: 5$ & Corn straw & Ethanol & $0.45 \mathrm{~g} / \mathrm{L}$ & Pang et al., 2018a \\
\hline $\begin{array}{l}\text { C. thermocellum ATCC27405, } \\
\text { Thermoanaerobacterium } \\
\text { thermosaccharolyticum DSM571 }\end{array}$ & $1: 0.815$ & Salix & Ethanol & $0.2 \mathrm{~g} / \mathrm{L}$ & Pang et al., 2018b \\
\hline $\begin{array}{l}\text { C. formicoaeetieum ATCC } 27076 \text {, } \\
\text { Streptococcus lactis }\end{array}$ & Unavailable & Whey lactose & Acetic acid & $20 \mathrm{~g} / \mathrm{L}$ & Tang et al., 1988 \\
\hline $\begin{array}{l}\text { C. thermocellum JN4, } \\
\text { Thermoanaerobacterium } \\
\text { thermosaccharolyticum GD17 }\end{array}$ & $5: 1$ & Cellulose & Hydrogen & $1.8 \mathrm{~mol} / \mathrm{mol}$ glucose & Liu et al., 2008 \\
\hline $\begin{array}{l}\text { C. cellulolyticum H10, R. palustris } \\
\text { CGA676 }\end{array}$ & $1: 1$ & Cellulose & Hydrogen & $1.4 \mathrm{~mol} / \mathrm{mol}$ glucose & Jiao et al., 2012 \\
\hline $\begin{array}{l}\text { C. cellulovorans } 743 \mathrm{~B} \text {, } \\
\text { Rhodopseudomonaspalustris } \\
\text { CGA009 }\end{array}$ & $1: 4$ & Cellulose & Hydrogen & $12.2 \pm 1.2 \mathrm{~mL} / \mathrm{day}$ & Lu and Lee, 2015 \\
\hline $\begin{array}{l}\text { C. thermocellum JN4, } \\
\text { T. thermosaccharolyticum GD17 }\end{array}$ & Unavailable & Cellulose & Hydrogen & $0.024 \mathrm{mmol} / \mathrm{h}$ & Wang et al., 2016 \\
\hline $\begin{array}{l}\text { C. cellulolyticum DSM5812, } \\
\text { Citrobacteramalonaticus }\end{array}$ & $1: 1$ & Corn stover & Hydrogen & $51.9 \mathrm{~L} \mathrm{H}_{2} / \mathrm{kg}$ total solid & Zhang et al., 2016b \\
\hline $\begin{array}{l}\text { C. thermoaceticum } 1745 \text {, } \\
\text { Methanosarcina sp. CHTI55 }\end{array}$ & $1: 1$ & Glucose & Methane & $17.31 \mathrm{ml} \mathrm{CH} 4 / \mathrm{g}$ cell/h & Nishio et al., 1990 \\
\hline $\begin{array}{l}\text { C. cellulovorans ATCC35296, } \\
\text { M. barkeri DSM804 }\end{array}$ & $1.4: 1$ & Cellulose & Methane & $\begin{array}{l}0.87 \pm 0.02 \mathrm{~mol} \mathrm{CH}_{4} / \mathrm{mol} \\
\text { glucose equivalent }\end{array}$ & Lu et al., 2017 \\
\hline $\begin{array}{l}\text { C. cellulovorans ATCC35296, } \\
\text { M. mazei DSM3647 }\end{array}$ & $1.7: 1$ & Cellulose & Methane & $\begin{array}{l}0.44 \pm 0.04 \mathrm{~mol} \mathrm{CH} \mathrm{CH}_{4} / \mathrm{mol} \\
\text { glucose equivalent }\end{array}$ & Lu et al., 2017 \\
\hline
\end{tabular}

acetic acid, and formic acid, which could be converted by M. barkeri to produce methane.

\section{Co-culture Systems of Solventogenic Clostridia \\ Hydrogen Production}

Solventogenic Clostridia are extensively used to produce hydrogen. Co-culture of two strains of solventogenic Clostridium was also studied (Table 3). Masset et al. used four pure Clostridia to compose three different co-cultures, (1) C. felsineum and C. pasteurianum, (2) C. felsineum and C. butyricum, (3) C. pasteurianum and C. butyricum, which produced hydrogen at higher rates than the mono-cultures, and the $\mathrm{H}_{2}$ yields were only slightly affected (Masset et al., 2012). In addition, Santilal explored the effect on hydrogen production by co-cultures of C. beijerinckii NCIMB6444 and C. butyricum NCIMB9578 from molasses and found that the accumulation of acetic acid and butyric acid severely inhibited the production of hydrogen. Hence, the co-culture was considered to create a possible negative interaction for hydrogen production (Santilal, 2015).

Combining heterotrophic anaerobic bacteria and anoxygenic phototrophic bacteria to produce hydrogen has attracted great attention, especially the co-culture of Clostridia with strains of Rhodopseudomonas or Rhodobacter. Clostridium spp. can use complex carbohydrates to produce organic acids and hydrogen through anaerobic digestion. In return, these organic acids can be utilized to increase hydrogen production by Rhodopseudomonas or Rhodobacter. Co-culture of Clostridium butyricum IFO3847 and Rhodobacter sphaeroides RV enhanced hydrogen production by $160 \%$ compared to the mono-culture of C. butyricum. However, research found that $\mathrm{NH}_{4}{ }^{+}$affected the accumulation of the reducing power that is essential for hydrogen production, and thus affected the hydrogen yield (Zhu et al., 2001). Chen et al. (2008) used a two-stage fermentation process in which the soluble metabolites produced by dark $\mathrm{H}_{2}$ fermentation were 
TABLE 3 | Overview of Clostridium co-cultures of solventogenic Clostridia in biotechnology applications.

\begin{tabular}{|c|c|c|c|c|c|}
\hline Applied micro-organisms & Inoculum ratios/size & Substrate & Product/process & Yield/production rates & References \\
\hline $\begin{array}{l}\text { C. butyricum IFO3847, } \\
\text { Rhodobacter sphaeroides RV }\end{array}$ & $1: 1$ & Glucose & Hydrogen & $\begin{array}{l}\text { Cumulative hydrogen } \\
106 \mathrm{~mL}\end{array}$ & Zhu et al., 2001 \\
\hline $\begin{array}{l}\text { C. butyricum DSM10702, } \\
\text { R. sphaeroides DSM158 }\end{array}$ & $1: 5.9$ & Glucose & Hydrogen & $\begin{array}{l}0.60 \mathrm{~mL} \text { hydrogen } / \mathrm{mL} \\
\text { medium }\end{array}$ & Fang et al., 2006 \\
\hline $\begin{array}{l}\text { C. pasteurianum } \mathrm{CH}_{4} \text {, } \\
\text { Rhodopseudomonaspalustris } \\
\text { WP3-5 }\end{array}$ & Unavailable & Sucrose & Hydrogen & $14.2 \mathrm{~mol} / \mathrm{mol}$ sucrose & Chen et al., 2008 \\
\hline $\begin{array}{l}\text { C. acetobutylicum } \mathrm{X}_{9} \text {, } \\
\text { Ethanoigenensharbinense } \mathrm{B}_{49}\end{array}$ & $1: 1$ & $\begin{array}{l}\text { Microcrystalline } \\
\text { cellulose }\end{array}$ & Hydrogen & 1810 ml/L medium & Wang et al., 2008 \\
\hline $\begin{array}{l}\text { C. butyricum, } \\
\text { Rhodopseudomonasfaecalis } \\
\text { RLD-53 }\end{array}$ & $1: 5$ & Glucose & Hydrogen & $4.134 \mathrm{~mol} / \mathrm{mol}$ glucose & Ding et al., 2009 \\
\hline $\begin{array}{l}\text { C. acidisoli sp. nov DSM12555, } \\
\text { R. sphaeroides ZX-5 }\end{array}$ & 0.83 & Sucrose & Hydrogen & $\begin{array}{l}10.16 \mathrm{~mol} / \mathrm{mol} \text { sucrose } \\
(5.08 \mathrm{~mol} / \mathrm{mol} \text { hexose) }\end{array}$ & Sun et al., 2010 \\
\hline $\begin{array}{l}\text { C. acetobutylicum, } \\
\text { R. sphaeroides }\end{array}$ & $1: 2$ & Food waste & Hydrogen & $22.7 \mathrm{~L}$ & Tavabe et al., 2010 \\
\hline $\begin{array}{l}\text { C. butyricum TISTR1032, } \\
\text { Enterobacter. aerogenes } \\
\text { TISTR1468 }\end{array}$ & $1: 1$ & Cassava pulp & Hydrogen & $\begin{array}{l}3385 \mathrm{ml} \mathrm{H}_{2} / \mathrm{L} \text { day and } \\
345.8 \mathrm{ml} \mathrm{H}_{2} / \mathrm{g} \mathrm{COD}_{\text {reduced }}\end{array}$ & Phowan et al., 2010 \\
\hline $\begin{array}{l}\text { C. beijerinckii L9, C. butyricum } \\
\text { M1 and B. thermoamylovorans } \\
\text { B5 }\end{array}$ & 8.9:4.8:10.3 & Yeast waste & Hydrogen & $\begin{array}{l}46 \mathrm{~mL} \mathrm{H}_{2} / g \text { COD added } \\
\text { yeast waste }\end{array}$ & Chou et al., 2011 \\
\hline $\begin{array}{l}\text { C. butyricum, E. coli K-12 } \\
\text { MG1655 }\end{array}$ & Unavailable & Glucose & Hydrogen & $1.65 \mathrm{~mol} / \mathrm{mol}$ glucose & Seppälä et al., 2011 \\
\hline $\begin{array}{l}\text { C. felsineum DSM749, } \\
\text { C. pasteurianum DSM525 }\end{array}$ & $1: 1$ & Glucose & Hydrogen & 1.5 L biogas/h & Masset et al., 2012 \\
\hline C. butyricum, R. sphaeroides & Unavailable & Glucose & Hydrogen & $15.9 \mathrm{~mL} \mathrm{H} / \mathrm{L} / \mathrm{h}$ & Lee et al., 2012 \\
\hline $\begin{array}{l}\text { C. beijerinckii NCIMB8052, } \\
\text { Geobacter metallireducens } \\
\text { GS-15 }\end{array}$ & $3: 1$ & Xylose & Hydrogen & $198.2 \pm 10.9 \mu \mathrm{mol}$ & Zhang et al., 2012 \\
\hline $\begin{array}{l}\text { C. beijerinckii NCIMB8052, } \\
\text { Geobacter metallireducens }\end{array}$ & Unavailable & Xylose & Hydrogen & $287 \pm 9 \mu \mathrm{mol}$ & $\begin{array}{l}\text { Zhang, 2013; Zhang } \\
\text { et al., } 2013\end{array}$ \\
\hline $\begin{array}{l}\text { C. butyricum ATCC19398, } \\
\text { R. palustris ATCC17001 }\end{array}$ & $1: 10$ & Sucrose & Hydrogen & $\begin{array}{l}\text { Cumulative hydrogen } \\
830 \mathrm{~mL}\end{array}$ & Kao et al., 2014 \\
\hline $\begin{array}{l}\text { C. beijerinckii NCIMB6444, } \\
\text { C. butyricum NCIMB9578 }\end{array}$ & $1: 1$ & Molasses & Hydrogen & $23.48 \mathrm{~mL} / \mathrm{L} / \mathrm{h}$ & Santilal, 2015 \\
\hline C. butyricum, R. sphaeroides N7 & $1: 1$ & Glucose & Hydrogen & $4.9 \mathrm{~mol} / \mathrm{mol}$ hexose & $\begin{array}{l}\text { Laurinavichene and } \\
\text { Tsygankov, } 2015\end{array}$ \\
\hline $\begin{array}{l}\text { C. acetobutylicum DSM792, } \\
\text { R. sphaeroides ATCC49419 }\end{array}$ & $1: 2$ & Glucose & Hydrogen & $6.22 \mathrm{~mol} / \mathrm{molglucose}$ & $\begin{array}{l}\text { Zagrodnik and Laniecki, } \\
2015\end{array}$ \\
\hline $\begin{array}{l}\text { C. acetobutylicum X9, } \\
\text { Ethanoigenens harbinense B2 }\end{array}$ & $1: 1$ & $\begin{array}{l}\text { Microcrystalline } \\
\text { cellulose }\end{array}$ & Hydrogen & 10.4 mmol/g MCC & Bao et al., 2016 \\
\hline $\begin{array}{l}\text { C. butyricum NRRLB- } 41122 \text {, } \\
\text { E. aerogenes NRRLB- } 407\end{array}$ & $1: 1$ & Crude glycerol & $\begin{array}{l}\text { Hydrogen, ethanol } \\
\text { and 1,3-propanedio }\end{array}$ & $\begin{array}{l}26.14 \mathrm{mmol} \mathrm{H} / \mathrm{L}, 1.4 \mathrm{~g} \\
\text { ethanol/L, } 0.5 \mathrm{~g} \\
\text { 1,3-propanediol/L }\end{array}$ & Pachapur et al., 2015a \\
\hline $\begin{array}{l}\text { C. butyricum NRRLB- } 41122 \text {, } \\
\text { E. aerogenes NRRLB- } 407\end{array}$ & $15 \%$ & $\begin{array}{l}\text { Crude glycerol and } \\
\text { apple pomace } \\
\text { hydrolyzate }\end{array}$ & Hydrogen & $26.07 \pm 1.57 \mathrm{mmol} / \mathrm{L}$ & Pachapur et al., 2015b \\
\hline $\begin{array}{l}\text { C. butyricum NRRLB- } 41122 \text {, } \\
\text { Enterobacter aerogenes } \\
\text { NRRLB- } 407\end{array}$ & $1: 1$ & $\begin{array}{l}\text { Crude glycerol and } \\
\text { eggshell biowaste }\end{array}$ & Hydrogen & $31.66 \pm 0.55 \mathrm{mmol} / \mathrm{L}$ & Pachapur et al., 2016a \\
\hline $\begin{array}{l}\text { C. butyricum NRRLB- } 41122 \text {, } \\
\text { Enterobacter aerogenes } \\
\text { NRRLB- } 407\end{array}$ & $1: 1$ & Biodiesel waste & Hydrogen & $32.1 \pm 0.03 \mathrm{mmol} / \mathrm{L}$ & Pachapur et al., 2016b \\
\hline $\begin{array}{l}\text { C. butyricum ATCC19398, } \\
\text { Rhodopseudomonas palustris } \\
\text { ATCC17001 }\end{array}$ & $1: 1$ & Sucrose & Hydrogen & $2.16 \mathrm{~mol} / \mathrm{mol}$ sucrose & Kao et al., 2016a \\
\hline
\end{tabular}


TABLE 3 | Continued

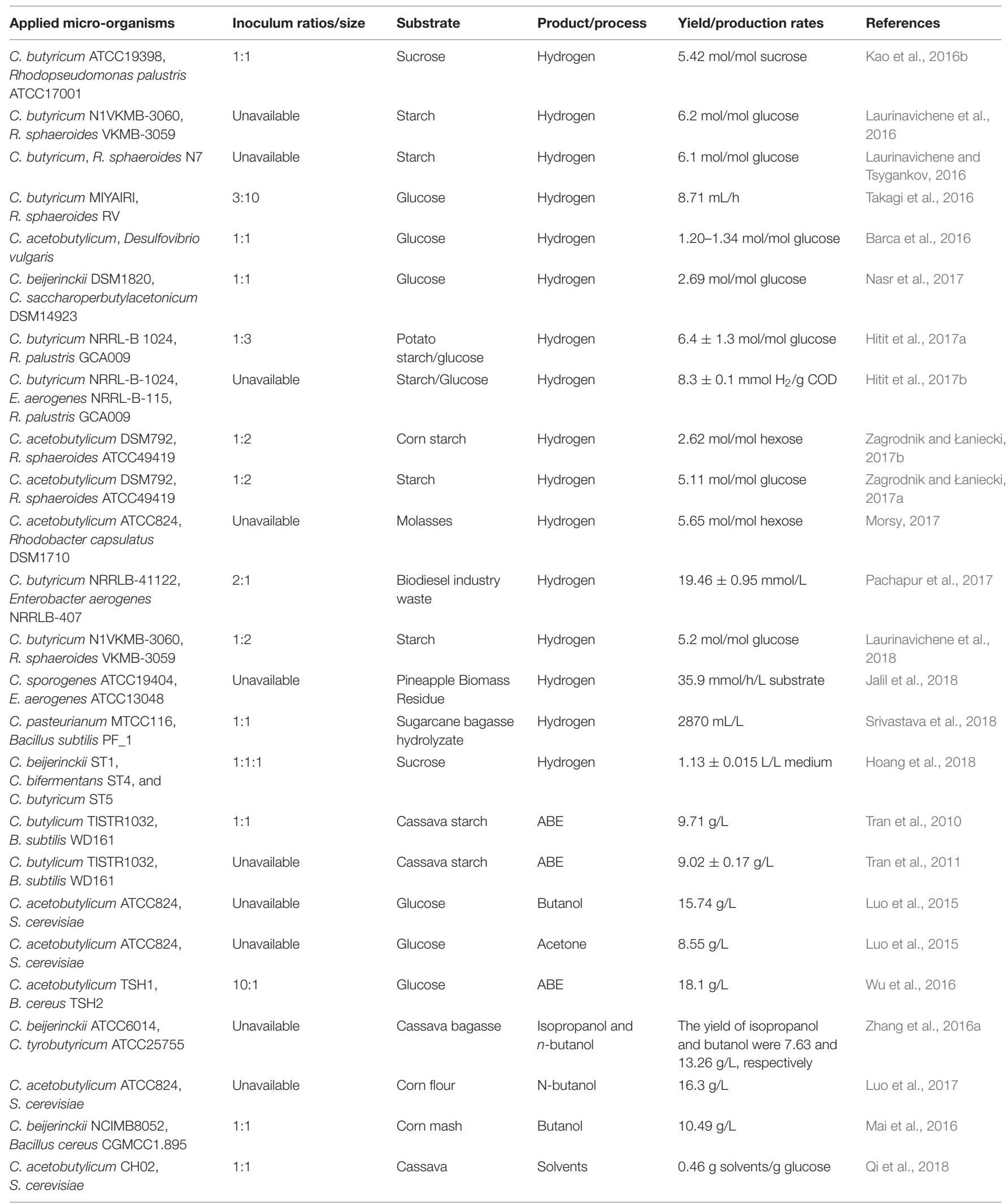


TABLE 3 | Continued

\begin{tabular}{|c|c|c|c|c|c|}
\hline Applied micro-organisms & Inoculum ratios/size & Substrate & Product/process & Yield/production rates & References \\
\hline $\begin{array}{l}\text { C. acetobutylicum TSH1, } \\
\text { B. cereus TSH2 }\end{array}$ & $1: 1$ & Glucose & Butanol & $12.3 \pm 0.9 \mathrm{~g} / \mathrm{L}$ & Mi et al., 2018 \\
\hline C. beijerinckii F-6, S. cerevisiae & $1: 1$ & Glucose & Butanol & $12.75 \mathrm{~g} / \mathrm{L}$ & Wu et al., 2019 \\
\hline $\begin{array}{l}\text { C. acetobutylicum ATCC824, } \\
\text { Bacillus subtilis CDBB555 }\end{array}$ & $2: 3$ & Agave hydrolyzates & Butanol & $8.28 \mathrm{~g} / \mathrm{L}$ & $\begin{array}{l}\text { Oliva-Rodríguez et al., } \\
2019\end{array}$ \\
\hline $\begin{array}{l}\text { C. acetobutylicum PTCC1492, } \\
\text { Nesterenkonia sp. strain F }\end{array}$ & $15: 1$ & Glucose & Butanol & $13.6 \mathrm{~g} / \mathrm{L}$ & Ebrahimi et al., 2019 \\
\hline $\begin{array}{l}\text { C. acetobutylicum ATCC824, } \\
\text { Fibrobacter succinogenes S85 }\end{array}$ & $3: 2$ & $\begin{array}{l}\text { Miscanthus } \\
\text { biomass }\end{array}$ & Solvents & $0.091 \mathrm{~g} / \mathrm{g}$ & Raut et al., 2019 \\
\hline $\begin{array}{l}\text { C. acetobutylicum ATCC824, } \\
\text { C. tetanomorphum ATCC } 49273\end{array}$ & $6.5: 6.5$ & $\begin{array}{l}\text { Sweet sorghum } \\
\text { juice }\end{array}$ & Lactic acid & $2.7 \mathrm{~g} / \mathrm{L}$ & Ndaba et al., 2015 \\
\hline $\begin{array}{l}\text { C. tyrobutyricum ATCC } 25755 \text {, } \\
\text { M. hexanoica }\end{array}$ & $1: 1$ & Fructose & Caproic acid & $0.69 \mathrm{~g} / \mathrm{L} / \mathrm{h}$ & Kim et al., 2018 \\
\hline
\end{tabular}

appropriately prediluted to avoid $\mathrm{NH}_{4}{ }^{+}$concentration inhibition before further use by photo fermentation in the co-culture of C. pasteurianum $\mathrm{CH}_{4}$ and Rhodopseudomonas palustris WP3-5. They achieved a stable continuous culture with an average $\mathrm{H}_{2}$ yield of $10.21 \mathrm{~mol} / \mathrm{mol}$ sucrose for nearly 10 days. Furthermore, the effect of the total volatile fatty acids concentration was greater than that of the $\mathrm{NH}_{4}-\mathrm{N}$ concentration (Kao et al., 2016a). At the same time, Laurinavichene and Tsygankov (2015) observed the inhibition of Clostridium by purple bacteria in which the purple bacteria could consume hydrogen produced by C. butyricum at early phase, thus reducing the hydrogen yield. Further, they found hydrogen production by $C$. butyricum in co-culture with Rhodobacter sphaeroides N7 was retarded as compared to the mono-culture after 3 days (Laurinavichene and Tsygankov, 2015) and confirmed that a high yeast extract concentration (160$320 \mathrm{mg} / \mathrm{L}$ ) enhanced reliable $\mathrm{H}_{2}$ production (Laurinavichene and Tsygankov, 2016; Laurinavichene et al., 2016). They used a repeated batch photofermentation utilizing starch with coculture of C. butyricum and R. sphaeroides N7 over 15 months to obtain efficient $\mathrm{H}_{2}$ production with an average $\mathrm{H}_{2}$ yield of $5.2 \mathrm{~mol} / \mathrm{mol}$ glucose with no accumulation of organic acids in the presence of Clostridia (Laurinavichene et al., 2018). The highest hydrogen yield of $6.4 \pm 1.3 \mathrm{~mol} / \mathrm{mol}$ glucose was achieved upon optimization of the culture conditions using response surface methodology in the co-culture system of C. butyricum NRRLB1024 and Rhodospeudomonas palustris GCA009 (Hitit et al., 2017a). Co-culturing C. acidisoli sp. nov DSM12555 and $R$. sphaeroides ZX-5 also gaved a relatively high hydrogen yield (Sun et al., 2010). In addition, C. acetobutylicum was extensively utilized in co-culture with Rhodobacter or Rhodopseudomonas species to produce hydrogen. The co-culture of C. acetobutylicum DSM792 and $R$. sphaeroides ATCC49419 produced a high $\mathrm{H}_{2}$ yield of $6.22 \mathrm{~mol} / \mathrm{mol}$ glucose utilizing glucose under optimal conditions (Zagrodnik and Laniecki, 2015).

In addition to the anaerobic photosynthetic bacteria, which remove metabolic inhibitors of Clostridia and increase hydrogen production, other dark-fermentative hydrogen-producing bacteria such as Ethanoligenens harbinense (Wang et al., 2008), Escherichia coli (Seppälä et al., 2011), Bacillus, and Enterobacter were also considered as partners to co-culture with Clostridia.
Not only can each of these bacteria be used as a biological fortifier to promote the production of hydrogen, but they also use a wide range of substrates, which has attracted wide attention. C. acetobutylicum $\mathrm{X}_{9}$, which can degrade microcrystalline cellulose with a typical butyrate-type fermentation metabolism and acetate and butyrate as primary metabolites, was cocultured with Ethanoigenens harbinense $\mathrm{B}_{49}$, which can produce hydrogen efficiently utilizing reduced sugar from the cellulose hydrolysis of $\mathrm{X}_{9}$. The co-culture hydrolyzed more cellulose and increased hydrogen production rates compared with the mono-culture of $\mathrm{X}_{9}$ using microcrystalline cellulose (Wang et al., 2008). Seppälä et al. (2011) co-cultured C. butyricum and Escherichia coli K-12 MG1655, which more efficiently utilized glucose although hydrogen production was lower than for C. butyricum mono-culture. In addition, facultative anaerobic Enterobacter aerogenes, which can act as a reducing agent to consume oxygen creating an anaerobic environment for obligate anaerobic Clostridia, has been extensively applied in a Clostridium co-culture system. Phowan et al. (2010) used the coculture of C. butyricum TISTR1032 and E. aerogenes TISTR1468 and found that it could reduce the lag time and produce hydrogen from cassava pulp hydrolyzate without any reducing agents in the medium. Moreover, co-culture of Enterobacter aerogenes and C. butyricum could also use crude glycerol and obtained a hydrogen production of $26.07 \pm 1.57 \mathrm{mmol} \mathrm{H}_{2} / \mathrm{L}$ of medium (Pachapur et al., 2015b). In addition, facultative anaerobic Bacillus was also utilized in a Clostridium co-culture. $B$. thermoamylovorans was found not only to consume oxygen to produce anaerobic conditions, but it also hydrolyzed complex substrates by secreting a variety of extracellular enzymes such as cellulase, $\alpha$-amylase, lipase, protease, and pectinase to stimulate the production of hydrogen by $C$. beijerinckii L9 from yeast waste (Chang et al., 2008; Chou et al., 2011).

In addition to co-culture with photosynthetic bacteria and facultative anaerobes to produce hydrogen, coculture with Geobacter metallireducens also demonstrated significant hydrogen production. Zhang found that coculturing G. metallireducens GS-15 and C. beijerinckii NCIMB8052 increased hydrogen production by $52.3 \%$, and the extent of substrate utilization by $39.0 \%$ (Zhang et al., 
2012). In addition, Barca et al. (2016) achieved a stable $\mathrm{H}_{2}$ production of $1.23 \pm 0.23 \mathrm{~mol} / \mathrm{mol}$ glucose after 34 days of operation using an up-flow anaerobic biofilm reactor by the co-culture of C. acetobutylicum ATCC824 and Desulfovibrio vulgaris. C. bifermentans ST4, newly isolated from cow rumen, was co-cultured with $C$. beijerinckii ST1 and $C$. butyricum ST5 to obtain hydrogen production of $1.13 \pm 0.015 \mathrm{~L} / \mathrm{L}$ medium (Hoang et al., 2018). These studies suggest that the development of new co-culture systems for Clostridia offers great potential for improving hydrogen production.

\section{Solvent Production}

Clostridium acetobutylicum, C. butyricum, and C. beijerinckii are typical solventogenic Clostridia that engage in $\mathrm{ABE}$ fermentation (Table 3). In a co-culture of solventogenic Clostridia and Bacillus, Bacillus not only provides an anaerobic environment for Clostridia by removing oxygen, but also increases the hydrolysis of complex substrates to promote the production of solvents, especially butanol (Tran et al., 2010; Tran et al., 2011; Wu et al., 2016; Mai et al., 2016; Oliva-Rodríguez et al., 2019). The co-culture of C. acetobutylicum TSH1 and Bacillus cereus TSH2 produced $11.2 \mathrm{~g} / \mathrm{L}$ butanol under microaerobic conditions ( $\mathrm{Wu}$ et al., 2016). Higher butanol yield was obtained by co-culturing solventogenic Clostridia and Saccharomyces cerevisiae. S. cerevisiae can not only use fermentable sugars to produce ethanol, but also secrete amino acids assimilated in and utilized by Clostridia to enhance the tolerance of Clostridia to higher butanol concentrations and increase of solvent yield (Luo et al., 2015, 2016, 2017; Qi et al., 2018; Wu et al., 2019). Luo et al. achieved high total ABE concentrations of $24.8 \mathrm{~g} / \mathrm{L}$ including $16.3 \mathrm{~g} / \mathrm{L}$ of butanol via the added butyrate fermentative supernatant produced by $C$. tyrobutyricum, which can produce butyric acid from fermentable sugars in the C. acetobutylicum ATCC824 and Saccharomyces cerevisiae co-culture (Luo et al., 2017). Moreover, C. tyrobutyricum was also co-cultured with $C$. beijerinckii ATCC6014 to increase butanol production (Zhang et al., 2016a). Recently, Ebrahimi et al. (2019) found the coculture of C. acetobutylicum and Nesterenkonia sp. strain F gave an efficient yield of $13.6 \mathrm{~g} / \mathrm{L}$ butanol under aerobic conditions, which further made it possible to avoid control of anaerobic conditions.

Notably, biological saccharification proved to be as promising as thermodynamic saccharification, which is of great significance for the direct production of target products using lignocellulosic materials. Raut utilized Fibrobacter succinogenes S85 with highly efficient saccharification ability found in the herbivore rumen, co-cultured with C. acetobutylicum ATCC824, and achieved a yield of $0.091 \mathrm{~g} / \mathrm{g}$ total solvents from miscanthus biomass. This provides a promising approach using biological saccharification to make lignocellulosic bio-fuels (Raut et al., 2019). In addition, co-culture of solventogenic Clostridia and other bacteria can also produce lactic acid (Ndaba et al., 2015), butyric acid, and caproic acid. The co-culture of C. tyrobutyricum and Bacillus sp. SGP1 gave a high yield of butyric acid $(34.2 \pm 1.8 \mathrm{~g} / \mathrm{L})$ from sucrose (Dwidar et al.,
2013). Moreover, C. tyrobutyricum can also be used to produce caproic acid. For example, the co-culture of C. tyrobutyricum and Megasphaera hexanoica, which is capable of producing caproic acid from acetic and butyric acids, gave $10.08 \mathrm{~g} / \mathrm{L}$ caproic acid using submerged hollow-fiber membrane bioreactors (Kim et al., 2018).

\section{Co-culture Systems of Acetogenic Clostridia and Chain-Elongating Clostridia}

Acetogenic Clostridia such as C. autoethanogenum and C. ljungdahli can convert $\mathrm{CO}_{2}$ or syngas to ethanol and acetate by employing the Wood-Ljungdahl pathway (WLP), which is the most effective and remarkable non-photosynthetic carbon fixation pathway. In the WLP, two molecules of $\mathrm{CO}_{2}$ are reduced (by $\mathrm{H}_{2}$ ) to form one molecule of acetyl-CoA (Abrini et al., 1994; Charubin et al., 2018). C. kluyveri is a typical chain-elongating Clostridium that employs reversed $\beta$-oxidation reactions to convert short chain fatty acids and ethanol into medium chain fatty acids and hydrogen (Charubin et al., 2018; Zou et al., 2018a). Co-culturing an acetogenic Clostridium and a chain-elongating Clostridium enables direct conversion of $\mathrm{CO}_{2}$ or syngas into high-value medium chain fatty acids (Table 4). Diender et al. established a coculture of C. autoethanogenum DSM10061 and C. kluyveri DSM555 using solely CO or syngas as the substrate and obtained butyrate and caproate, and butanol and hexane. Furthermore, they found that caproate toxicity is one of the severe culture problems and that controlling the $\mathrm{pH}$ or supporting a continuous process may improve production (Diender et al., 2016).

Furthermore, co-culturing acetogenic Clostridia or chainelongating Clostridia with other microorganisms has proved to have great potential in improving solvent production performance. In the co-culture of C. kluyveri $\mathrm{H} 068$ and Methanogen 166 from ethanol and acetate, the Methanogen 166 strain converted accumulated hydrogen produced by C. kluyveri $\mathrm{H} 068$ into $\mathrm{CH}_{4}$, thus eliminating the hydrogenmediated feedback inhibition of C. kluyveri H068 and enhancing caproic acid production (Yan and Dong, 2018). C. aceticum is a homoacetogen that grows chemolithotrophically from $\mathrm{H}_{2}$ and $\mathrm{CO}_{2}$ and achieves product yield stoichiometrically via the WLP, and it was co-cultured with cellulolytic C. cellulovorans. This system utilized cellulosic biomass to produce solvents and an acetate yield of $1.011 \mathrm{~g} / \mathrm{L}$ was obtained upon optimization of the $\mathrm{pH}$ (Xia et al., 2017). In addition, co-culturing with solventogenic Clostridia has also been investigated. Co-culturing C. carboxidivorans NCIMB15243, which can utilize $\mathrm{CO}_{2}$ and $\mathrm{H}_{2}$ via the reductive acetyl-CoA pathway or the WLP to produce organic acids, such as acetate and butyrate, and alcohols, such as ethanol and butanol, and C. beijerinckii NCIMB8052 achieved ethanol and butanol production from $\mathrm{CO}_{2}$ and $\mathrm{H}_{2}$ (Youn, 2017). Li and Henson (2019) co-cultured C. autoethanogenum and the human gut bacterium Eubacterium rectale, which can convert acetic acid into butyric acid, improving the butyrate productivity from carbon monoxide. 
TABLE 4 | Overview of Clostridium co-cultures of acetogenic Clostridia or chain elongating Clostridia in biotechnology applications.

\begin{tabular}{|c|c|c|c|c|c|}
\hline Applied micro-organisms & Inoculum ratios/size & Substrate & Product/process & Yield/production rates & References \\
\hline $\begin{array}{l}\text { C. autoethanogenum } \\
\text { DSM10061, C. kluyveri DSM555 }\end{array}$ & $1: 1$ & $\begin{array}{l}\text { Carbon monoxide } \\
\text { or syngas }\end{array}$ & $\begin{array}{l}\text { Medium-chain fatty } \\
\text { acids and higher } \\
\text { alcohols }\end{array}$ & $\begin{array}{l}\text { Butyrate and caproate were } \\
\text { at a rate of } 8.5 \pm 1.1 \text { and } \\
2.5 \pm 0.63 \mathrm{mmol} / \mathrm{L} / \text { day, } \\
\text { butanol and hexanol at a } \\
\text { rate of } 3.5 \pm 0.69 \text { and } \\
2.0 \pm 0.46 \mathrm{mmol} / \mathrm{L} / \text { day }\end{array}$ & Diender et al., 2016 \\
\hline $\begin{array}{l}\text { C. ljungdahlii PETC, C. kluyveri } \\
\text { DSM555 }\end{array}$ & $2: 1$ & Syngas & $\begin{array}{l}\text { Butanol, hexanol, } \\
\text { and octanol }\end{array}$ & $\begin{array}{l}\text { The net volumetric } \\
\text { production rates of } \\
n \text {-butanol, } n \text {-hexanol, and } \\
n \text {-octanol were } 39.2,31.7 \text {, } \\
\text { and } 0.045 \mathrm{mmol} /\llcorner/ \mathrm{d} \text {, } \\
\text { respectively }\end{array}$ & Richter et al., 2016 \\
\hline $\begin{array}{l}\text { C. carboxidivorans NCIMB15243, } \\
\text { C. beijerinckii NCIMB8052 }\end{array}$ & $1: 1$ & $\mathrm{CO}_{2}$ and $\mathrm{H}_{2}$ & Butanol & $2.309 \mathrm{~g} / \mathrm{L}$ & Youn, 2017 \\
\hline C. aceticum, C. cellulovorans & Unavailable & Cellulose & Acetate & $1.011 \mathrm{~g} / \mathrm{L}$ & Xia et al., 2017 \\
\hline $\begin{array}{l}\text { C. Kluyveri H068, Methanogen } \\
166\end{array}$ & $2: 1$ & $\begin{array}{l}\text { Acetate and } \\
\text { ethanol }\end{array}$ & Caproic acid & $435.72 \pm 13.58 \mathrm{mg} / 100 \mathrm{~mL}$ & Yan and Dong, 2018 \\
\hline $\begin{array}{l}\text { C. autoethanogenum } \\
\text { DSM10061, C. kluyveri DSM555 }\end{array}$ & $1: 20$ & Syngas & $\begin{array}{l}\text { Butyrate and } \\
\text { caproate }\end{array}$ & $\begin{array}{l}\text { The butyrate and caproate } \\
\text { concentrations were } \\
5.5 \pm 0.7 \mathrm{mM} \text { and } \\
1.3 \pm 0.3 \mathrm{mM} \text {, respectively }\end{array}$ & Diender et al., 2019 \\
\hline
\end{tabular}

\section{MICROBIAL INTERACTION MECHANISMS IN Clostridium CO-CULTURE SYSTEMS}

\section{Methods Used to Study Microbial Interactions}

Monitoring the biomass of bacteria in a Clostridium co-culture system is considered to be an effective strategy for monitoring the stability of the system. In addition to the traditional plate culture method of counting colony-forming units (CFU), which is time consuming, and fluorescence microscopy counting (Jiao et al., 2012), which is unable to distinguish bacteria that share similar morphology, the fluorescence in situ hybridization (FISH) method (Fang et al., 2006), spectrophotometer detection (Ding et al., 2009; Xu and Tschirner, 2014), qPCR analysis method (Geng et al., 2010; Sun et al., 2010; Zhang et al., 2012; Salimi and Mahadevan, 2013; Wen et al., 2014a,b; Benomar et al., 2015; $\mathrm{Lu}$ and Lee, 2015; Wu et al., 2016) have been used to analyze the dynamic abundances of microorganisms in a Clostridium co-culture system.

In addition, other molecular techniques have been used for systematic monitoring to elucidate interactions or to obtain metabolic strategies for improving the fermentation performance of the Clostridium co-culture system. Luo et al. utilized a real-time fluorescence quantitative PCR analysis method to measure the transcriptional levels of the $\operatorname{ctf} A B$ gene in different batches of $C$. acetobutylicum in a co-culture. They found that the transcriptional levels of $\operatorname{ctf} A B$ significantly increased with exogenous acetate addition as compared with those of the control, which showed that the increases of $\operatorname{ctf} A B$ transcriptional levels also enhanced acetone bio-synthesis in ABE fermentations (Luo et al., 2015). Lu et al. (2016) used next-generation sequencing technology to explore the global transcriptomic responses of the co-culture obtaining C. cellulovorans 743B and Rhodopseudomonas palustris CGA009. They analyzed and compared gene expression levels of in the co-cultures and the mono-cultures during the early-, mid-, and late-exponential growth phases respectively via genome-wide transcriptome sequencing. The results indicated the nitrogen fixation genes of $R$. palustris CGA009 and the cellulosomal genes of C. cellulovorans 743B were upregulated in co-culture, which contributed to a better understanding and optimization of the hydrogen-producing co-culture systems (Lu et al., 2016). In addition, RT-PCR was used to analyze the expression levels of key pathway genes to better understand the interactions in the Clostridium co-culture system (Benomar et al., 2015; Wang et al., 2016; Lu et al., 2017). Furthermore, flow cytometry, fluorescence microscopy, scanning electron microscopy (SEM), and a specific genetic marker were also utilized to elucidate bacterial strain interactions in the Clostridium co-culture system (Benomar et al., 2015; Pachapur et al., 2016a). Charubin and Papoutsakis established a transwell system utilizing a permeable membrane allowing metabolite exchange between both compartments and used quantitative PCR (qPCR) for population analysis and RTqPCR for gene expression analysis. They found that unique, direct cell-to-cell interactions between $C$. acetobutylicum and C. ljungdahlii led to electron exchange and metabolite exchange, and changed the gene-expression patterns between partner organisms (Charubin and Papoutsakis, 2019). Sander et al. (2017) developed and validated an effective protocol to determine selected redox- and energy-related metabolite concentrations, including intracellular $\mathrm{NAD}(\mathrm{H}), \mathrm{NADP}(\mathrm{H}), \mathrm{ATP}, \mathrm{ADP}$, and AMP in C. thermocellum and T. saccharolyticum co-culture, which can clarify the redox state of these cofactors and help identify a strategy to achieve higher bioproductivity. Moreover, proteomic analysis and comparative transcriptome analysis were also applied to the Clostridium co-culture system to obtain 
strategies for improving fermentation performance (Mi et al., 2018; Diender et al., 2019).

\section{Use of Complementary Metabolic Pathways}

Most of the systems discussed entail a synergistic interaction in the Clostridium co-culture system. Understanding microbial interactions will lead to improvements in the monitoring and control over the system stability. It is the complementary metabolic pathways that exist in many co-culture systems that achieve the conversion of substrates into target products. In this case, one bacterium may convert complex macromolecular substrates such as lignocellulosic raw materials, starchy raw materials, crude glycerol, or gases such as carbon monoxide and syngas into substrates such as soluble sugars and acids, which also function as nutrients or precursors that can be used by the companion bacterium to produce the desired final products. For example, cellulolytic Clostridia degrade complex lignocellulosic substrates into soluble sugars that can be used by solventogenic Clostridia to produce solvents. Anoxygenic phototrophic bacteria such as Rhodopseudomonas or Rhodobacter utilize acetic acid and butyric acid produced by solventogenic Clostridia from soluble saccharides such as glucose, sucrose, and starch to produce hydrogen (Figure 1A). Or in the co-culture system of an acetogenic Clostridium and a chain-elongating Clostridium, the acetogenic Clostridium converts $\mathrm{CO}_{2}$ or syngas to ethanol and acetate employing the WLP, and the chain-elongating Clostridium such as C. kluyveri converts short-chain fatty acids plus ethanol into mediumchain fatty acids, such as butyrate and caproate, and higher alcohols and hydrogen via a reversed $\beta$-oxidation metabolism. Complementary interactions of metabolic pathways broaden the scope of substrate utilization and can produce target products more economically.

\section{Removal of Metabolic Inhibitors}

As Clostridia are strict anaerobic bacteria, the removal of oxygen by associated bacteria suppresses oxygen toxicity and plays a necessary role in co-culture and stable fermentation. This type of microbial co-culture system provides protection from environmental influences (Bader et al., 2010). It has been reported that many types of associated bacteria such as Bacillus, Enterobacter, Saccharomyces cerevisiae (Figure 1B) (Zuroff et al., 2013), Candida molischiana (Zuroff et al., 2013), Caldibacillus debilis (Wushke et al., 2015), and Nesterenkonia sp. F (Ebrahimi et al., 2019) have the ability to remove oxygen, creating anaerobic conditions for Clostridium. In addition to removing oxygen to maintain an anaerobic environment, the removal of other metabolic inhibitors plays a critical role in the stability of a co-culture. For instance, in co-culture systems of C. cellulolyticum and C. amalonaticus, C. cellulolyticum can hydrolyze corn stover to release glucose and xylose, which are quickly utilized by $C$. amalonaticus to produce hydrogen. Formate, an inhibitor of C. cellulolyticum growth, is also consumed by $C$. amalonaticus and transformed into hydrogen (Zhang et al., 2016b).

\section{Cofactor Complementation}

Cofactors are non-protein compounds that combine with enzymes and reactants to promote their activation and accelerate enzymatic reactions (Qin et al., 2009). Sato et al. (1992) confirmed that Vitamin $\mathrm{B}_{12}$ is beneficial to $C$. thermocellum ethanol production from cellulose. In the co-cultures of cellulolytic C. thermocellum and non-cellulolytic Thermoanaerobacter strains (X514 and 39E), strain X514 improved ethanolic fermentation more effectively than strain $39 \mathrm{E}$ in co-culture, resulting in higher ethanol production by at least $62 \%$ in X514 co-cultures than in $39 \mathrm{E}$ co-cultures. Comparative genome sequence analysis revealed that the higher ethanol production efficiency of X514 compared with strain 39E was related to the presence of a complete vitamin $\mathrm{B}_{12}$ biosynthesis pathway (Figure 1C). Moreover, the ethanol production in strain 39E coculture improved by $203 \%$ following the addition of exogenous vitamin $B_{12}$ (Qiang et al., 2011).

\section{Interspecies Hydrogen and Electron Transfer}

Interspecies hydrogen transfer that does not require physical interaction in cellulose-to-methane co-cultures combining cellulolytic Clostridia and methanogens has also been reported (Collet et al., 2003, 2005). In the co-culture of cellulolytic Clostridia and Methanosarcina barkeri Fusaro, Methanosarcina mazei, and Methanothermobacter thermautotrophicus, the methanogen utilized hydrogen and carbon dioxide, acetic acid, and even formic acid that was generated by the cellulolytic Clostridia from cellulose to produce methane (Sasaki et al., 2012; Lu et al., 2017). Moreover, interspecies hydrogen transfer between many hydrogen-producing Clostridium bacteria and methanogenic archaea has also been confirmed in the strong flavor baijiu ecosystem (Zou et al., 2018b). In addition, the interspecies hydrogen transfer interaction between acetogenic Clostridia (C. aceticum, C. carboxidivorans) and cellulolytic Clostridia/solventogenic Clostridia has also been confirmed. Acetogenic Clostridia convert $\mathrm{H}_{2}$ and $\mathrm{CO}_{2}$ that were produced by cellulolytic Clostridia/solventogenic Clostridia to acetate and butyric acid and butanol as the final products using the WLP (Xia et al., 2017; Youn, 2017).

A direct interspecies electron transfer mechanism has recently been characterized in Geobacter species, which maintain electron balance with other species through physical contact (Moscoviz et al., 2017). In co-culture systems of C. pasteurianum and Geobacter sulfurreducens, C. pasteurianum is the sole electron acceptor. G. sulfurreducens transfers electrons to C. pasteurianum and triggers a prominent metabolic shift of C. pasteurianum, which enhances 1,3-propanediol production at the expense of butanol and ethanol (Moscoviz et al., 2017). In addition, indirect interspecies electron transfer in co-culture of C. beijerinckii and Geobacter metallireducens has been reported in which G. metallireducens utilizes AQDS as the electron acceptor, regenerating extracellular electron shuttles of anthrahydroquinone-2, 6-disulfonate $\left(\mathrm{AH}_{2} \mathrm{QDS}\right)$, which is oxidized to AQDS by $C$. beijerinckii. $\mathrm{AH}_{2} \mathrm{QDS}$ regeneration resulted in changes in the intracellular $\mathrm{NADH} / \mathrm{NAD}^{+}$ratio 


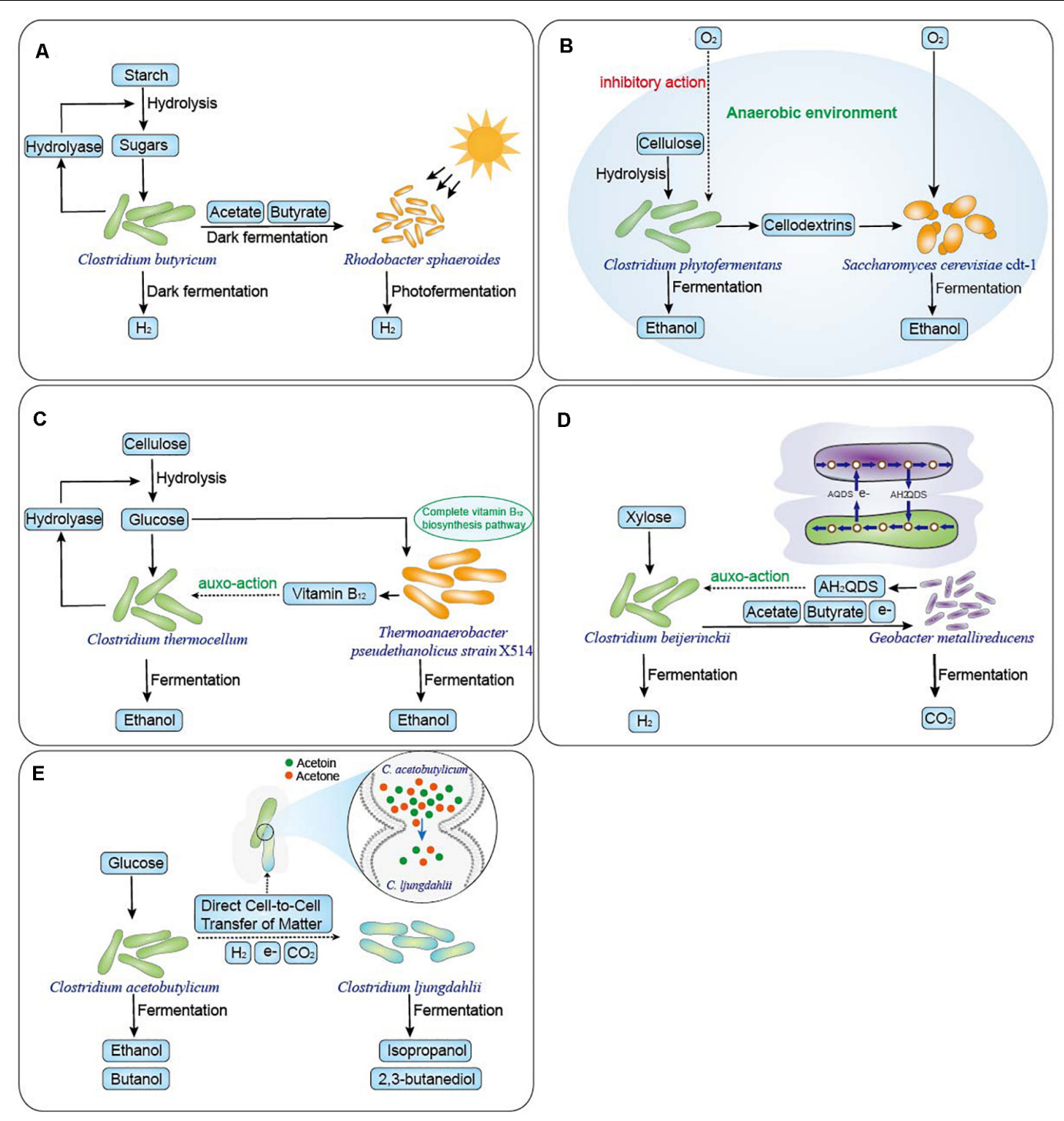

FIGURE 1 | Schematic diagram of five type microbial interaction mechanisms which were shown to improve Clostridium co-culture systems. (A) Use of complementary metabolic pathways. Rhodobacter sphaeroides converts the acetate and butyrate produced by C. butyricum into hydrogen $\left(6.2 \mathrm{~mol} \mathrm{H}_{2} / \mathrm{mol}\right.$ glucose) by photo fermentation from starch (Laurinavichene et al., 2016). (B) Removal of metabolic inhibitors. Yeast consume oxygen, creating an anaerobic environment in which $C$. phytofermentans produces ethanol from cellulose and obtaining high ethanol yield of $22 \mathrm{~g} / \mathrm{L}$ with stable symbiotic relationship by controlling oxygen transport of approximately $8 \mu \mathrm{mol} / \mathrm{L}$ hour (Zuroff et al., 2013). (C) Cofactor complementation. Thermoanaerobacter strains X514 with a complete vitamin $\mathrm{B}_{12}$ biosynthesis pathway significantly enhances ethanolic fermentation of cellulolytic Clostridium thermocellum (Qiang et al., 2011). (D) Interspecies hydrogen and electron transfer. G. metallireducens oxidizes acetate and butyrate to regenerate $\mathrm{AH}_{2} \mathrm{QDS}$, significantly improving $\mathrm{C}$. beijerinckii fermentation of hydrogen from xylose (Zhang et al., 2012). (E) Direct cell-to-cell material exchange. Direct cell-to-cell interactions and material exchange of acetone and acetoin between C. acetobutylicum ATCC824 and C. ljungdahlii ATCC55383 with direct electron transfer results in non-native metabolites production (Charubin and Papoutsakis, 2019).

in C. beijerinckii that enhanced biohydrogen production from xylose (Figure 1D) (Zhang et al., 2012).

\section{Direct Cell-to-Cell Material Exchange}

Benomar et al. (2015) demonstrated that nutrient deficiencies of lactate and sulfate resulting in starvation of Desulfovibrio vulgaris triggered tight cell-to-cell interactions with Clostridia and material transfer. Physical evidence of aggregation between the two strains was observed by flow cytometry and was further investigated by fluorescence microscopy by labeling bacteria in the co-culture. In addition, a partial of peptidoglycan labelled with fluorochromes (green fluorescence) where the two strains occurred physical contact was observed by fluorescence microscopy and the tight cell-to-cell interactions were also observed by the SEM. When calcein-labeled D. vulgaris and C. acetobutylicum ATCC824 were co-cultured, calcein could be transferred in either direction between $D$. vulgaris and C. acetobutylicum cytoplasm. And when D. vulgaris with a pRD3 plasmid containing the gene mCherry (green fluorescent protein) was co-cultured with $C$. acetobutylicum without the 
mCherry gene but labeled with calcein, both bacteria exhibited both green and red fluorescence, which demonstrated they could exchange larger molecules such as proteins in the co-culture. In addition, the interspecies molecular exchange induced modifications of gene expression and changes in metabolism that resulted in an increase in hydrogen yield (Benomar et al., 2015). At the same time, Charubin et al. also confirmed direct cell-to-cell interactions and material exchange of acetone and acetoin between C. acetobutylicum ATCC824 and C. ljungdahlii ATCC55383 and, combined with direct electron transfer, it changed the gene-expression patterns of both partner organisms. This resulted in the production of non-native metabolites such as isopropanol and 2,3-butanediol (Figure 1E) (Charubin and Papoutsakis, 2019).

\section{STRATEGIES TO ENHANCE THE STABILITY AND EFFICIENCY OF Clostridium CO-CULTURE SYSTEMS}

\section{Strategy for Optimizing the Fermentation Process}

In the Clostridium co-culture system, the optimization of fermentation parameters such as $\mathrm{pH}$, temperature, inoculum ratio, medium components, inoculation time, and control of anaerobic conditions plays an important role in the improvement and stability of co-culture yield. Among various parameters, the $\mathrm{pH}$ of the medium is one of the essential factors affecting cell growth and product yield; furthermore, changing the medium $\mathrm{pH}$ may induce a metabolic shift (Rabemanolontsoa et al., 2016). For example, it was demonstrated that high $\mathrm{pH}$ limits dark fermentation, and low $\mathrm{pH}$ limits light fermentation. Eventually $\mathrm{pH} 7$ was determined to be the best condition for bacterial cooperation during a combined process to produce hydrogen through optimization of a co-culture of solventogenic Clostridia and anoxygenic phototrophic bacteria (Zagrodnik and Laniecki, 2015). In addition, adjustment of the phosphate buffer concentration (Laurinavichene and Tsygankov, 2016), adopting a fixed $\mathrm{pH}$ value (Zagrodnik and Laniecki, 2015), and addition of exogenous regulators such as eggshell biowaste (Pachapur et al., 2016a) were also shown to be good $\mathrm{pH}$ control strategies in many Clostridium co-culture systems. Moreover, co-culture of immobilized cells will be less affected by changes in medium $\mathrm{pH}$ and thus promote system stability and yield, which is also considered a good strategy ( $\mathrm{Xu}$ and Tschirner, 2014).

Temperature control also has a great effect on the growth and production of the two bacteria in a co-culture and is an important optimization parameter in the fermentation process. Generally speaking, the common range of optimal temperature between the two bacteria is the parameter value range, and the optimal temperature value is obtained according to the fermentation performance. Another temperature control strategy is to inoculate high-temperature bacteria at high temperature for fermentation after a period of time, then lower the temperature to the temperature appropriate for the second bacterium, and then inoculate the second bacteria at that temperature for fermentation, such as in the co-culture of thermophilic C. thermocellum and mesophilic bacteria (Yu et al., 1985; Nakayama et al., 2011; Lin et al., 2013; Kiyoshi et al., 2015).

At the same time, the inoculation ratio is also considered when optimizing the product yield and improving the system stability in the Clostridium co-culture system. In the co-culture of C. cellulovorans and C. acetobutylicum from lignocellulosic substrates, under the condition of optimized inoculation rate at the inoculation ratio 5:3 (Cc: $\mathrm{Ca}$ ), both strains established a synergistic relationship that resulted in the 2- to 3-fold hydrogen production improvement than the mono-cultures of C. acetobutylicum (Valdez-Vazquez et al., 2019). Meanwhile, inoculation time is usually optimized for a co-culture with cellulolytic Clostridia, especially in the co-culture of thermophilic cellulolytic C. thermocellum and mesothermal bacteria (Yu et al., 1985; Nakayama et al., 2011; Wen et al., 2014a,b), co-culture with facultative anaerobic bacteria (Yu et al., 1985; Nakayama et al., 2011; Wen et al., 2014a,b; Ebrahimi et al., 2019; Wu et al., 2019), and co-culture of solventogenic Clostridia and acetogenic Clostridia from $\mathrm{CO}_{2}$ and $\mathrm{H}_{2}$ (Youn, 2017). $\mathrm{Li}$ and Liu optimized the $C$. thermosaccharolyticum inoculation time in $125-\mathrm{mL}$ anaerobic bottles and obtained the maximum hydrogen yield of $68.2 \mathrm{~mL} / \mathrm{g}$ corn stalk when C. thermosaccharolyticum was inoculated $24 \mathrm{~h}$ earlier than $C$. thermocellum. And they successfully scaled up the hydrogen fermentation process from $125-\mathrm{mL}$ anaerobic bottles to an 8 - $\mathrm{L}$ continuous stirred tank reactor (Li and Liu, 2012).

Pachapur et al. (2017) demonstrated that each of the medium components played an important role in producing higher hydrogen in a co-culture system compared with a mono-culture. A complete metabolic pathway shift from a reductive to an oxidative pathway in glycerol fermentation was controlled by the medium composition, such as the concentrations of components $\mathrm{KH}_{2} \mathrm{PO}_{4}$ and $\mathrm{MgSO}_{4} .7 \mathrm{H}_{2} \mathrm{O}$, with decreased 1,3-propandiol (1,3$\mathrm{PD}$ ) production further increasing the hydrogen yield (Pachapur et al., 2017). Media components can act as activators to increase enzyme activity and also as cofactors for different enzymes during hydrogen production (Alshiyab et al., 2008). In order to meet the nutritional requirements and improve the yield of bacteria in coculture, the composition of the medium was optimized, especially the substrate concentration (Ebrahimi et al., 2019). Kao et al. (2016a) utilized different sucrose concentrations of 4.45, 8.9, 17.8, and $35.6 \mathrm{~g} / \mathrm{L}$ to investigate the effect on hydrogen production in the immobilized co-culture of C. butyricum and R. palustris. They found that the hydrogen production decreased gradually with sucrose concentration increasing from $4.45 \mathrm{~g} / \mathrm{L}$ to $35.6 \mathrm{~g} / \mathrm{L}$, and the maximum hydrogen production of $5.42 \mathrm{~mol} / \mathrm{mol}$ sucrose was acquired at $4.45 \mathrm{~g} / \mathrm{L}$ sucrose, which showed high sucrose concentrations inhibited hydrogen production (Kao et al., 2016b). At the same time, the concentration of yeast extract has also been shown to have a significant effect on hydrogen production in co-culture of C. butyricum and $R$. sphaeroides (Laurinavichene and Tsygankov, 2016; Laurinavichene et al., 2016). In most cases, the co-culture medium contained growth factors necessary for the normal growth and metabolism of the two bacteria, or metal ions, trace elements and vitamins etc., in addition to different substrates, to maintain the stability of 
the co-culture and the performance of the fermented products (Ding et al., 2009). Recently, the method of mixing components of the medium at different proportions and selecting the best mixing ratio according to the fermentation performance was also used to optimize the medium, which is mainly explored in new co-cultures (Xia et al., 2017; Raut et al., 2019).

Due to differences in the metabolic capacities of Clostridium species in co-culture systems, the addition of different metabolites or cofactors can be used to regulate the metabolism of one or more microorganisms and further significantly influence the fermentation performance of the co-culture system. In a co-culture system of $C$. thermocellum and a noncellulolytic Thermoanaerobacter strain (39E), the addition of $30 \mu \mathrm{g} / \mathrm{L}$ vitamin $\mathrm{B}_{12}$ improved ethanol production by 203\% (Qiang et al., 2011). In addition, electron shuttling compounds, which are organic molecules that can cycle between oxidized and reduced forms and transfer electrons from a lower redox potential electron donor to a higher redox potential electron acceptor (Ye et al., 2011), may be added. Intracellular electron shuttles, such as nicotinamide adenine dinucleotide $\left(\mathrm{NAD}^{+}\right)$, ubiquinone, ferredoxin, and cytochromes, play an essential role in the electron transport chain of microorganisms (Zhang, 2013). They were proved to increase the hydrogen yield and xylose utilization by increasing the acetate/butyrate ratio during acidogenic stages of C. beijerinckii. C. beijerinckii utilized electron shuttles to redirect carbon and electron flow to targeted pathways in the fermentative metabolism, which is a potentially viable strategy to improve hydrogen production in the co-culture system of C. beijerinckii and G. metallireducens (Ye et al., 2011; Zhang et al., 2012; Zhang, 2013). Alternative extracellular electron shuttles, including lawsone, juglone, indigo dye, humic acids, and fulvic acids, were also found to be able to substitute for $\mathrm{AH}_{2} \mathrm{QDS}$, enhancing hydrogen production of the co-culture system (Zhang et al., 2013).

In the absence of an expensive reductant and nitrogen spraying, the synergies of co-culture systems can provide better process-based economic strategies for product production and larger field-scale applications. In addition, the elimination of a nitrogen sparging step was proved to be a process improvement strategy that resulted in changes in the metabolic pathways of the strain with increases of $\mathrm{H}_{2}$ /ethanol/lactate and decreases of 1,3-PD production (Pachapur et al., 2015a). In a general way, facultative anaerobic bacteria will remove dissolved oxygen from the medium and oxygen from the reactor to provide an anaerobic environment for strictly anaerobic Clostridia in a closed reactor without reductants and nitrogen spraying. Zuroff et al. (2013) established a more stable obligate mutualism coculture including $C$. phytofermentans and $S$. cerevisiae cdt-1 consuming oxygen to provide respiratory protection to the obligate anaerobe by controlling the volumetric transport rate of oxygen at approximately $8 \mu \mathrm{mol} \mathrm{O}_{2} / \mathrm{L}$ hour. Recently, a better companion bacterium was found that could not only remove oxygen but also exhibited an excellent synergistic effect, making it possible for Clostridia to ferment whether in an anaerobic environment or an aerated environment. The combination of Nesterenkonia and C. acetobutylicum formed a powerful "co-culture" for butanol production without oxygen removal measures before fermentation (Ebrahimi et al., 2019).

The pretreatment of substrates and the co-utilization of various substrates have also been shown to significantly improve the yield ( $\mathrm{Li}$ et al., 2014; Pachapur et al., 2015b, 2016b; Rabemanolontsoa et al., 2016; Zhang et al., 2016b). Rabemanolontsoa et al. (2016) achieved a high carbon conversion efficiency of $84.9 \%$ utilizing hot-compressed water treatment of Japanese cedar in co-culture of $C$. thermoaceticum and C. thermocellum that produces acetic acid. The addition of Tween 80 to crude glycerol decreased the crude glycerol viscosity and improved its solubility and bioavailability, which improved the glycerol utilization rate and resulted in increasing hydrogen production by about 1.25-fold in the co-culture of Enterobacter aerogenes and C. butyricum from biodiesel waste (Pachapur et al., 2016b). Moreover, the co-culture of Enterobacter aerogenes and $C$. butyricum could also use crude glycerol to obtain hydrogen production of $26.07 \pm 1.57 \mathrm{mmol} \mathrm{H}_{2} / \mathrm{L}$ of medium in the presence of apple pomace hydrolyzate as the indirect $\mathrm{H}$-acceptor. A shift of metabolite pathway from the reductive to the oxidative route caused a production decrease of 1,3$\mathrm{PD}$ and production increase of butyrate conducive to hydrogen production (Pachapur et al., 2015b). And Srivastava et al. (2018) utilized graphene oxide to treat thermostable crude cellulose that had been obtained via fungal co-cultivation of the strains Cladosporium cladosporioides NS2 and Emericella variecolor NS3 using a mixed substrate of orange peel and rice straw under solid state fermentation. Then they used sugarcane bagasse hydrolyzate from the graphene oxide-treated thermostable crude cellulose to co-culture C. pasteurianum MTCC116 and Bacillus subtilis PF_1 to obtain hydrogen production, which provided a novel strategy to enhance biohydrogen production (Srivastava et al., 2018).

\section{Cell Immobilization and New Fermentation Equipment}

In addition to the optimization of the fermentation conditions, cell immobilization is also considered a potential strategy for improving the stability of the Clostridium co-culture system as it can provide moderate conditions for microbial growth and minimize the effects of system inhibitors (Laxman Pachapur et al., 2015). Jalil et al. (2018) gained a biohydrogen production rate of $35.9 \mathrm{mmol} / \mathrm{h} / \mathrm{L}$ substrate utilizing pineapple biomass residue by using an immobilized co-culture of C. sporogenes ATCC19404 and Enterobacter aerogenes ATCC13048. They found that using an activated carbon sponge provided a better support material compared to loofah sponge, as they could enhance the production rate by approximately $67 \%$ compared to the free cell co-culture (Jalil et al., 2018).

The fermentation process and equipment have also been proved to be of great significance in improving the performance of Clostridium co-cultures (Table 5). Morsy developed a continuous fermentation system by controlling the hydraulic retention time to avoid substrate inhibition and achieved sustainable hydrogen production of $5.56 \mathrm{~mol} \mathrm{H}_{2} / \mathrm{mol}$ hexose with C. acetobutylicum ATCC824 and Rhodobacter capsulatus 
TABLE 5 | Strategies for enhanced Clostridium co-culture systems.

\begin{tabular}{|c|c|c|c|c|}
\hline Regulation strategies & Products & $\begin{array}{l}\text { Composition of Clostridium } \\
\text { co-culture system }\end{array}$ & Results & References \\
\hline Vitamin $\mathrm{B}_{12}$ addition & Ethanol & $\begin{array}{l}\text { C. thermocellum, } \\
\text { Thermoanaerobacter strains } 39 \mathrm{E}\end{array}$ & $\begin{array}{l}\text { Ethanol production was improved } \\
\text { by } 203 \% \text { when adding } 30 \mu \mathrm{g} / \mathrm{L} \\
\text { vitamin } B_{12} \text {. }\end{array}$ & Qiang et al., 2011 \\
\hline $\begin{array}{l}\text { Deletion of } L d h \text { and Pta and adaptive } \\
\text { evolution for } 2,000 \mathrm{~h}\end{array}$ & Ethanol & $\begin{array}{l}\text { C. thermocellum, } \\
\text { Thermoanaerobacterium } \\
\text { saccharolyticum }\end{array}$ & $\begin{array}{l}\text { A stable strain with } 40: 1 \text { ethanol } \\
\text { selectivity was obtained and the } \\
\text { ethanol yield increased by } \\
4.2 \text {-fold. }\end{array}$ & Argyros et al., 2011 \\
\hline Control of oxygen delivery (OTR) & Ethanol & $\begin{array}{l}\text { C. phytofermentans, S. cerevisiae } \\
\text { cdt-1 }\end{array}$ & $\begin{array}{l}\text { Maintenance of populations of } \\
10^{5} \text { to } 10^{6} \mathrm{CFU} / \mathrm{mL} \text { for } 50 \text { days. }\end{array}$ & Zuroff et al., 2013 \\
\hline Immobilization & Ethanol & $\begin{array}{l}\text { C. thermocellum ATCC27405, } \\
\text { C. thermolacticum ATCC } 43739\end{array}$ & $\begin{array}{l}\text { The ethanol yield increased by } \\
\text { over } 60 \% \text { than free cell } \\
\text { fermentation. }\end{array}$ & Xu and Tschirner, 2014 \\
\hline $\begin{array}{l}\text { Optimization of substrate } \\
\text { concentration, initial } \mathrm{pH} \text {, and inoculum } \\
\text { ratio }\end{array}$ & Hydrogen & $\begin{array}{l}\text { C. acidisoli DSM12555, } \\
\text { R. sphaeroides ZX-5 }\end{array}$ & $\begin{array}{l}\text { The yield of hydrogen was } \\
10.16 \mathrm{~mol} / \mathrm{mol} \text { sucrose } \\
(5.08 \mathrm{~mol} / \mathrm{mol} \text { hexose })\end{array}$ & Sun et al., 2010 \\
\hline $\begin{array}{l}\text { Utilization of automatic experimental } \\
\text { setting }\end{array}$ & Hydrogen & $\begin{array}{l}\text { C. butyricum, E. coli K-12 } \\
\text { MG1655 }\end{array}$ & $\begin{array}{l}\text { Improvement of experimental } \\
\text { monitoring }\end{array}$ & Seppälä et al., 2011 \\
\hline $\begin{array}{l}\text { Optimization of } \mathrm{pH} \text { and utilization of a } \\
\text { repeated fed-batch run }\end{array}$ & Hydrogen & C. butyricum, R. sphaeroides & $\begin{array}{l}\text { The hydrogen production rate } \\
\text { was } 15.9 \mathrm{ml} / \mathrm{L} / \mathrm{h} \text {. }\end{array}$ & Lee et al., 2012 \\
\hline $\begin{array}{l}\text { Utilization of continuous stirred tank } \\
\text { reactor (CSTR) }\end{array}$ & Hydrogen & $\begin{array}{l}\text { C. thermocellum DSM7072, } \\
\text { C. thermosaccharolyticum } \\
\text { DSM869 }\end{array}$ & $\begin{array}{l}\text { The yield of hydrogen was } \\
\text { improved by } 9.8 \% \text {. }\end{array}$ & Li and Liu, 2012 \\
\hline $\begin{array}{l}\text { Optimization of } \mathrm{pH} \text { and utilization of } \\
20 \mathrm{~L} \text { batch bioreactors }\end{array}$ & Hydrogen & C. butyricum, C. pasteurianum & $\begin{array}{l}\text { The yield of hydrogen was } \\
2.91 \mathrm{~mol} / \mathrm{mol} \text { hexose. }\end{array}$ & Masset et al., 2012 \\
\hline $\begin{array}{l}\text { Immobilization and optimization of initial } \\
\mathrm{pH}\end{array}$ & Hydrogen & $\begin{array}{l}\text { C. butyricum ATCC19398, } \\
\text { R. palustris ATCC17001 }\end{array}$ & $\begin{array}{l}\text { The yield was improved by } \\
19.8 \% \text {. }\end{array}$ & Kao et al., 2014 \\
\hline $\begin{array}{l}\text { Dynamic microwave-assisted alkali } \\
\text { pretreatment (DMAP) of cornstalk and } \\
\text { optimization of the key factors affecting } \\
\text { pretreatment process }\end{array}$ & Hydrogen & $\begin{array}{l}\text { C. thermocellum DSM7072, } \\
\text { C. thermosaccharolyticum } \\
\text { DSM869 }\end{array}$ & $\begin{array}{l}\text { The effective removal of lignin and } \\
\text { the released soluble compounds } \\
\text { increased. }\end{array}$ & Li et al., 2014 \\
\hline $\begin{array}{l}\text { Utilization of an up-flow anaerobic } \\
\text { packed-bed reactor (APBR) }\end{array}$ & Hydrogen & $\begin{array}{l}\text { C. acetobutylicum ATCC } 824 \text {, } \\
\text { Desulfovibrio vulgaris }\end{array}$ & $\begin{array}{l}\text { The hydrogen yield was } \\
1.20 \pm 0.26 \mathrm{~mol} / \mathrm{mol} \text { glucose. }\end{array}$ & Barca et al., 2016 \\
\hline $\begin{array}{l}\text { Substrate pretreatment of adding } \\
\text { Tween } 80\end{array}$ & Hydrogen & $\begin{array}{l}\text { C. butyricum NRRL B-41122, } \\
\text { E. aerogenes NRRL B-407 }\end{array}$ & $\begin{array}{l}\text { Hydrogen production increased } \\
\text { around } 1.25 \text {-fold in the presence } \\
\text { of Tween } 80 \text {. }\end{array}$ & Pachapur et al., 2016b \\
\hline $\begin{array}{l}\text { Substrate pretreatment of } \\
\text { steam-exploded corn stover }\end{array}$ & Hydrogen & $\begin{array}{l}\text { C. cellulolyticum DSM5812, } \\
\text { Citrobacter amalonaticus Y19 }\end{array}$ & $\begin{array}{l}\text { The yield of hydrogen was } \\
51.9 \mathrm{~L} / \mathrm{kg} \text { total solid. }\end{array}$ & Zhang et al., 2016b \\
\hline $\begin{array}{l}\text { Optimization of microorganism ratio and } \\
\text { substrate and buffer concentrations }\end{array}$ & Hydrogen & $\begin{array}{l}\text { C. butyricum NRRL-B1024, } \\
\text { R. palustris GCA009 }\end{array}$ & $\begin{array}{l}\text { The yield of hydrogen was } \\
6.4 \pm 1.3 \mathrm{~mol} / \mathrm{mol} \text { glucose. }\end{array}$ & Hitit et al., 2017a \\
\hline $\begin{array}{l}\text { Utilization of continuous fermentation } \\
\text { system (CFS) }\end{array}$ & Hydrogen & $\begin{array}{l}\text { C. acetobutylicum ATCC824, } \\
\text { Rhodobacter capsulatus } \\
\text { DSM1710 }\end{array}$ & $\begin{array}{l}\text { The } \mathrm{H}_{2} \text { yield was } 5.65 \mathrm{~mol} / \mathrm{mol} \\
\text { hexose. }\end{array}$ & Morsy, 2017 \\
\hline Immobilization & Hydrogen & $\begin{array}{l}\text { C. sporogenes ATCC19404, } \\
\text { E. aerogenes ATCC13048 }\end{array}$ & $\begin{array}{l}\text { The hydrogen production rate } \\
\text { was } 35.9 \mathrm{mmol} / \mathrm{h} / \mathrm{L}_{\text {substrate }} \text {. }\end{array}$ & Jalil et al., 2018 \\
\hline Medium optimization & $\mathrm{ABE}$ & $\begin{array}{l}\text { C. butylicum TISTR1032, } \\
\text { B. subtilis WD161 }\end{array}$ & The ABE yield was $9.71 \mathrm{~g} / \mathrm{L}$. & Tran et al., 2010 \\
\hline Medium optimization & $\mathrm{ABE}$ & $\begin{array}{l}\text { C. butylicum TISTR1032, } \\
\text { B. subtilis WD161 }\end{array}$ & $\begin{array}{l}\text { The ABE production was } \\
\text { improved by } 2.2 \text {-fold. }\end{array}$ & Tran et al., 2011 \\
\hline $\begin{array}{l}\text { Optimization of inoculation timing, } \\
\text { inoculation ratio, and pH control }\end{array}$ & $\mathrm{ABE}$ & $\begin{array}{l}\text { C. cellulovorans 743B, } \\
\text { C. beijerinckii NCIMB8052 }\end{array}$ & $\begin{array}{l}\text { The ABE yield were } 19.9 \mathrm{~g} / \mathrm{L} \\
\text { (acetone } 3.96 \text {, butanol } 10.9 \text {, and } \\
\text { ethanol } 5.04 \mathrm{~g} / \mathrm{L} \text { ). }\end{array}$ & Wen et al., 2014a \\
\hline $\begin{array}{l}\text { Pretreatment feedstock of optimizing } \\
\text { particle size }\end{array}$ & $\mathrm{ABE}$ & $\begin{array}{l}\text { C. thermocellum ATCC27405, } \\
\text { C. beijerinckii ATCC51743 }\end{array}$ & $\begin{array}{l}\text { Fermentation performance } \\
\text { improvement of } 670 \mathrm{~mL} \text { gas. }\end{array}$ & Flythe et al., 2015 \\
\hline Acetate addition & $\mathrm{ABE}$ & C. acetobutylicum, S. cerevisiae & $\begin{array}{l}\text { The Acetone concentration } \\
\text { increased to } 8.27-8.55 \mathrm{~g} / \mathrm{L} \text {, and } \\
\text { the butanol concentration also } \\
\text { increased to } 13.91-14.23 \mathrm{~g} / \mathrm{L} \\
\text { simultaneously. }\end{array}$ & Flythe et al., 2015 \\
\hline
\end{tabular}


TABLE 5 | Continued

\begin{tabular}{|c|c|c|c|c|}
\hline Regulation strategies & Products & $\begin{array}{l}\text { Composition of Clostridium } \\
\text { co-culture system }\end{array}$ & Results & References \\
\hline Exogenous cellulase enzyme addition & Butanol & $\begin{array}{l}\text { C. thermocellum ATCC27405, } \\
\text { C. saccharoperbutylacetonicm } \\
\text { ATCC13564 }\end{array}$ & $\begin{array}{l}\text { The yiled of butanol was } \\
\text { significantly increased to } 6.9 \mathrm{~g} / \mathrm{L} \\
\text { using } 40 \mathrm{~g} / \mathrm{L} \text { of delignified rice } \\
\text { straw. }\end{array}$ & Kiyoshi et al., 2015 \\
\hline Butyrate addition & Butanol & $\begin{array}{l}\text { C. acetobutylicum ATCC } 824 \text {, } \\
\text { Saccharomyces cerevisiae }\end{array}$ & $\begin{array}{l}\text { The butanol concentration and } \\
\text { butanol/acetone ratio were } \\
15.74 \mathrm{~g} / \mathrm{L} \text { and } 2.83 \text {, respectively. }\end{array}$ & Kiyoshi et al., 2015 \\
\hline Controlled oxygen delivery & Butanol & $\begin{array}{l}\text { C. acetobutylicum } \mathrm{TSH} 1 \text {, } \\
\text { B. cereus } \mathrm{TSH} 2\end{array}$ & The yield of butanol was $11.2 \mathrm{~g} / \mathrm{L}$. & Wu et al., 2016 \\
\hline $\begin{array}{l}\text { Utilization of an immobilized-cell } \\
\text { fermentation system }\end{array}$ & $\begin{array}{l}\text { Isopropanol and } \\
n \text {-butanol }\end{array}$ & $\begin{array}{l}\text { C. beijerinckii ATCC } 6014 \text {, } \\
\text { C. tyrobutyricum ATCC } 25755\end{array}$ & $\begin{array}{l}\text { The yields of isopropanol and } \\
\text { butanol were } 6.78 \text { and } 12.33 \mathrm{~g} / \mathrm{L} \text {, } \\
\text { respectively. }\end{array}$ & Zhang et al., 2016a \\
\hline Continuous co-culture & $\begin{array}{l}\text { Butanol, hexanol, } \\
\text { and octanol }\end{array}$ & $\begin{array}{l}\text { C. ljungdahlii PETC, C. kluyveri } \\
\text { DSM555 }\end{array}$ & $\begin{array}{l}\text { The net rates of } N \text {-butyrate and } \\
n \text {-caproate were } 129 \text { and } \\
70 \mathrm{mmol} \mathrm{C} / \mathrm{L} / \mathrm{d} \text {, respectively and } \\
\text { the net rates of } n \text {-butanol, } \\
n \text {-hexanol, and } n \text {-octanol were } \\
39.2,31.7 \text {, and } \\
0.045 \mathrm{mmolC} / \mathrm{L} / \mathrm{d} \text {, respectively. }\end{array}$ & Richter et al., 2016 \\
\hline $\begin{array}{l}\text { Addition of butyrate fermentative } \\
\text { supernatant of } C \text {. tyrobutyricum }\end{array}$ & $n$-butanol & $\begin{array}{l}\text { C. acetobutylicum ATCC } 824 \text {, } \\
\text { S. cerevisiae }\end{array}$ & $\begin{array}{l}\text { Final butanol and total } \mathrm{ABE} \\
\text { concentrations reached of } 16.3 \\
\text { and } 24.8 \mathrm{~g} / \mathrm{L} \text {. }\end{array}$ & Luo et al., 2017 \\
\hline $\begin{array}{l}\text { Deletion of the cell division-related gene } \\
\text { maf and neutral red addition, and } \\
\text { temperature optimization }\end{array}$ & Butanol & $\begin{array}{l}\text { C. acetobutylicum TSH1, } \\
\text { B. cereus TSH2 }\end{array}$ & The yield was $13.9 \pm 1.0 \mathrm{~g} / \mathrm{L}$ & Mi et al., 2018 \\
\hline $\begin{array}{l}\text { Optimization of inoculation amount/time } \\
\text { and media formulation }\end{array}$ & Butanol & $\begin{array}{l}\text { C. acetobutylicum PTCC1492, } \\
\text { Nesterenkonia sp. F }\end{array}$ & The yield was $13.6 \mathrm{~g} / \mathrm{L}$. & Ebrahimi et al., 2019 \\
\hline $\begin{array}{l}\text { Optimization of initial } \mathrm{pH} \text { and } \\
\text { inoculation amount/time of } S \text {. cerevisiae }\end{array}$ & Butanol & C. beijerinckiiF-6, S. cerevisiae & $\begin{array}{l}\text { The yield was } 12.75 \mathrm{~g} / \mathrm{L} \text { and the } \\
\text { productivity was } 0.454 \mathrm{~g} / \mathrm{L} / \mathrm{h} \text {. }\end{array}$ & Wu et al., 2019 \\
\hline $\begin{array}{l}\text { Hot-compressed water treatment of } \\
\text { Japanese cedar }\end{array}$ & Acetic acid & $\begin{array}{l}\text { C. thermoaceticum, } \\
\text { C. thermocellum ATCC } 27405\end{array}$ & Conversion efficiency of $84.9 \%$ & $\begin{array}{l}\text { Rabemanolontsoa et al., } \\
2016\end{array}$ \\
\hline $\begin{array}{l}\text { Utilization of two submerged } \\
\text { hollow-fiber membrane bioreactors } \\
\text { (s-HF/MBRs) }\end{array}$ & Caproic acid & $\begin{array}{l}\text { C. tyrobutyricum, Megasphaera } \\
\text { hexanoica }\end{array}$ & $\begin{array}{l}\text { The yield was } 10.08 \mathrm{~g} / \mathrm{L} \text { and the } \\
\text { productivity was } 0.69 \mathrm{~g} / \mathrm{L} / \mathrm{h} \text {. }\end{array}$ & Kim et al., 2018 \\
\hline $\begin{array}{l}\text { Utilization of continuous stirred-tank } \\
\text { reactors (CSTR) }\end{array}$ & $\begin{array}{l}\text { Chain elongated } \\
\text { products }\end{array}$ & $\begin{array}{l}\text { C. autoethanogenum } \\
\text { DSM10061, C. kluyveri DSM555 }\end{array}$ & $\begin{array}{l}\text { The yields of butyrate and } \\
\text { caproate were } 5.5 \pm 0.7 \mathrm{mM} \text { and } \\
1.3 \pm 0.3 \mathrm{mM} \text {, respectively. }\end{array}$ & Diender et al., 2019 \\
\hline $\begin{array}{l}\text { Utilization of Continuous stirred tank } \\
\text { bioreactor (CSTBR) }\end{array}$ & Butyrate & $\begin{array}{l}\text { C. autoethanogenum, } \\
\text { Eubacterium rectale or C. kluyveri }\end{array}$ & $\begin{array}{l}\text { Higher volumetric productivities } \\
\text { and lower substrate inhibition. }\end{array}$ & Li and Henson, 2019 \\
\hline
\end{tabular}

DSM1710 (Morsy, 2017). And Li and Henson established a metabolic modeling of co-culture systems in anaerobic continuous stirred tank bioreactors (CSTBRs) to assess the COto-butyrate conversion in the co-culture of C. autoethanogenum and C. kluyveri. They predicted the system could enhance both butyrate productivity and titer (Li and Henson, 2019). Furthermore, good reactor and process design can not only achieve continuous and high yield product output, but also play a crucial role in maintaining the system stability through accurate monitoring and control of the culture in real time (Seppälä et al., 2011; Diender et al., 2019). The establishment of a continuously fed bioprocessing step involving in-line product extraction via gas stripping and product condensing within the syngas recirculation line achieved continuous butanol, hexanol, and octanol production from syngas and showed good stability in the co-culture of $C$. ljungdahlii and C. kluyveri (Richter et al., 2016).

\section{Genetic Modification}

Various metabolic engineering tools have been developed for cellulolytic, solventogenic, acetogenic, and acidogenic Clostridia for gene overexpression, downregulation, and inactivation (Cheng et al., 2019). For example, the exogenous genes of celA and celD, which encode two glycoside hydrolases of Neocallimastix patriciarum, were separately cloned into C. beijerinckii NCIMB8052 (López-Contreras et al., 2001), which was applied in a Clostridium co-culture system. Antisense RNA for gene downregulation of the expression of the hydrogen-uptake hydrogenase gene (hupCBA) in C. saccharoperbutylacetonicum caused the hupCBA mutant strain to exhibit higher hydrogen production and lower butanol production compared to the parent strain C. saccharoperbutylacetonicum when co-cultured with C. thermocellum. The molecular selection of hydrogenase gene activity proved to be a potential strategy for strains 
producing higher butanol ratios (Nakayama et al., 2013). A NifA mutant strain resulting in constitutive nitrogenase activity and $\mathrm{H}_{2}$ production in Rhodopseudomonas palustris CGA676 was utilized to improve hydrogen production from cellulose in the Clostridium co-culture system (Jiao et al., 2012). Argyros et al. (2011) deleted the genes responsible for organic acid formation encoding lactate dehydrogenase (Ldh) and phosphotransacetylase (Pta) of C. thermocellum and obtained a stable strain with 40:1 ethanol selectivity and a 4.2-fold increase of ethanol yield over the wild-type strain after it evolved for $2,000 \mathrm{~h}$. The co-culture of organic acid-deficient engineered strains of both C. thermocellum and T. saccharolyticum produced $38 \mathrm{~g} / \mathrm{L}$ ethanol from $92 \mathrm{~g} / \mathrm{L}$ avicel, with the production of acetic and lactic acids below detection limits, in $146 \mathrm{~h}$ (Argyros et al., 2011). At the same time, Mi et al. disrupted the maf gene with unknown function of $C$. acetobutylicum TSH1, and added Bacillus cereus TSH2 to form a new symbiotic co-culture system, resulting in an $8.9 \%$ butanol titer improvement from $12.3 \pm 0.9$ to $13.4 \pm 1.1 \mathrm{~g} / \mathrm{L}$ compared to the original symbiotic partnership (Mi et al., 2018). In addition, other different genetic manipulation strategies such as plasmid-based gene overexpression, antisense RNA for gene downregulation, gene inactivation via homologous recombination etc. are expected to be used to improve the stability and performance of co-culture systems through a better understanding of co-culture interactions at the molecular level based on systems biology methods.

\section{CONCLUSION}

Clostridium co-culture systems can use extensive biomassderived carbohydrates, fixing $\mathrm{CO}_{2}$ autotrophically, enabling maximum carbon substrate utilization, and achieving very high metabolite yields (Charubin et al., 2018), making them of great significance to the production of many important products, such as hydrogen, butanol, and methane, and energy development. Further improvements to the productivity of coculture systems will require a comprehensive understanding of the physiological characteristics and interaction mechanisms of individual members and entire co-culture systems. Fortunately, genome sequencing technology has greatly improved our understanding of the functions and genetic background of Clostridium species (Zou et al., 2018b). Other systems biology

\section{REFERENCES}

Abrini, J., Naveau, H., and Nyns, E. J. (1994). Clostridium autoethanogenum, sp. nov., an anaerobic bacterium that produces ethanol from carbon monoxide. Arch. Microbiol. 161, 345-351. doi: 10.1007/bf00303591

Alshiyab, H., Kalil, M. S., Hamid, A. A., and Yusoff, W. M. W. (2008). Trace metal effect on hydrogen production using C. acetobutylicum. Online J Biol. Sci. 8, 1-9. doi: 10.3844/ojbsci.2008.1.9

Argyros, D. A., Tripathi, S. A., Barrett, T., Rogers, S. R., Feinberg, L., Olson, D. G., et al. (2011). High ethanol titers from cellulose by using metabolically engineered thermophilic, anaerobic microbes. Appl. Microbiol. Biotechnol. 77, 8288-8294. doi: 10.1128/aem.00646-11

Bader, J., Mast-Gerlach, E., Popoviæ, M. K., Bajpai, R., and Stahl, U. (2010). Relevance of microbial coculture fermentations in biotechnology. J. Appl. Microbiol 109, 371-387. doi: 10.1111/j.1365-2672.2009.04659.x approaches could also be applicable to the comprehensive analysis of the physiological characteristics of Clostridia in co-culture systems (Ivey et al., 2013; Lu et al., 2017). Furthermore, genome-scale metabolic models, which contain all the metabolic information of a single organism or ecosystem (Zhang et al., 2013; Moscoviz et al., 2017), can be used to understand physiological characteristics and interspecies interactions (Tran et al., 2010). Salami et al. (2010) developed a genome-scale metabolic model of C. cellulolyticum in a co-culture with $C$. acetobutylicum, and suggested that cellobiose inhibition is not the main factor responsible for improved cellulose utilization compared with the mono-culture of C. cellulolyticum. Systems biology could contribute to major advances in the understanding of fermentation regulation, molecular modifications, and synthesis of artificial microecosystems in the future. Combining physiological experiments, molecular analysis, systems biology, and bioinformatics will allow us to fully understand the interaction mechanisms of co-culture systems, and the use of synthetic biology to build new artificial microbial ecosystems for the production of desired products is likely to be a trend in the future.

\section{AUTHOR CONTRIBUTIONS}

YD and WZ conceived, designed, and wrote the manuscript. WZ, KZ, GY, and JY helped to draft and revise the manuscript. All the authors read and approved the final manuscript.

\section{FUNDING}

This work was supported by grants from the National Natural Science Foundation of China (Grant No. 31801522), the Industry-University-Research Cooperation Project of Wuliangye Group Co., Ltd., and Sichuan University of Science and Engineering (CXY2019ZR011).

\section{ACKNOWLEDGMENTS}

We thank International Science Editing (http://www.inter nationalscienceediting.com) for editing this manuscript.

Bao, H., Chen, C., Jiang, L., Liu, Y., Shen, M., Liu, W., et al. (2016). Optimization of key factors affecting biohydrogen production from microcrystalline cellulose by the co-culture of Clostridium acetobutylicum $\mathrm{X} 9+$ Ethanoigenens harbinense B2. RSC Adv. 6, 3421-3427. doi: 10.1039/C5RA14192C

Barca, C., Ranava, D., Bauzan, M., Ferrasse, J.-H., Giudici-Orticoni, M.-T., and Soric, A. (2016). Fermentative hydrogen production in an up-flow anaerobic biofilm reactor inoculated with a co-culture of Clostridium acetobutylicum and Desulfovibrio vulgaris. Bioresour. Technol. 221, 526-533. doi: 10.1016/j.biortech. 2016.09.072

Benomar, S., Ranava, D., Cárdenas, M. L., Trably, E., Rafrafi, Y., Ducret, A., et al. (2015). Nutritional stress induces exchange of cell material and energetic coupling between bacterial species. Nat. Commun. 6, 6283. doi: 10.1038/ ncomms 7283

Chang, J. J., Chou, C. H., Ho, C. Y., Chen, W. E., Lay, J. J., and Huang, C. C. (2008). Syntrophic co-culture of aerobic Bacillus and anaerobic Clostridium for 
bio-fuels and bio-hydrogen production. Int. J. Hydrogen Energy 33, 5137-5146. doi: 10.1016/j.ijhydene.2008.05.021

Charubin, K., Bennett, R. K., Fast, A. G., and Papoutsakis, E. T. (2018). Engineering Clostridium organisms as microbial cell-factories: challenges \& opportunities. Metab. Eng. 50, 173-191. doi: 10.1016/j.ymben.2018. 07.012

Charubin, K., and Papoutsakis, E. T. (2019). Direct cell-to-cell exchange of matter in a synthetic Clostridium syntrophy enables $\mathrm{CO} 2$ fixation, superior metabolite yields, and an expanded metabolic space. Metab. Eng. 52, 9-19. doi: 10.1016/j. ymben.2018.10.006

Chen, C. Y., Yang, M. H., Yeh, K. L., Liu, C. H., and Chang, J. S. (2008). Biohydrogen production using sequential two-stage dark and photo fermentation processes. Int. J. Hydrogen Energy 33, 4755-4762. doi: 10.1016/ j.ijhydene.2008.06.055

Cheng, C., Bao, T., and Yang, S. T. (2019). Engineering clostridium for improved solvent production: recent progress and perspective. Appl. Microbiol. Biotechnol. 103, 5549-5566. doi: 10.1007/s00253-019-09916-7

Chou, C.-H., Han, C.-H., Chang, J.-J., and Lay, J. J. (2011). Co-culture of Clostridium beijerinckii L9, Clostridium butyricum M1 and Clostridium butyricum B5 for converting yeast waste into hydrogen. Int. J. Hydrogen Energy 36, 13972-13983. doi: 10.1016/j.ijhydene.2011.03.067

Collet, C., Gaudard, O., Péringer, P., and Schwitzguébel, J. P. (2005). Acetate production from lactose by Clostridium thermolacticum and hydrogenscavenging microorganisms in continuous culture-effect of hydrogen partial pressure. J. Biotechnol. 118, 328-338. doi: 10.1016/j.jbiotec.2005.05.011

Collet, C., Schwitzguébel, J. P., and Péringer, P. (2003). Improvement of acetate production from lactose by growing Clostridium thermolacticum in mixed batch culture. J. Appl. Microbiol. 95, 824-831. doi: 10.1046/j.1365-2672.2003. 02060.x

Diender, M., Olm, I. P., Gelderloos, M., Koehorst, J. J., Schaap, P. J., Stams, A. J., et al. (2019). Metabolic shift induced by synthetic co-cultivation promotes high yield of chain elongated acids from syngas. Sci. Rep. 9:18081. doi: 10.1038/ s41598-019-54445-y

Diender, M., Stams, A. J. M., and Sousa, D. Z. (2016). Production of mediumchain fatty acids and higher alcohols by a synthetic co-culture grown on carbon monoxide or syngas. Biotechnol. Biofuels 9:82. doi: 10.1186/s13068-016-0495-0

Ding, J., Liu, B. F., Ren, N. Q., Xing, D. F., Guo, W. Q., Xu, J. F., et al. (2009). Hydrogen production from glucose by co-culture of Clostridium butyricum and immobilized Rhodopseudomonas faecalis RLD-53. Int. J. Hydrogen Energy 34, 3647-3652. doi: 10.1016/j.ijhydene.2009.02.078

Dwidar, M., Kim, S., Jeon, B. S., Um, Y., Mitchell, R. J., and Sang, B. I. (2013). Co-culturing a novel Bacillus strain with Clostridium tyrobutyricum ATCC 25755 to produce butyric acid from sucrose. Biotechnol. Biofuels 6:35. doi: 10.1186/1754-6834-6-35

Ebrahimi, E., Amiri, H., Asadollahi, M. A., and Shojaosadati, S. A. (2019). Efficient butanol production under aerobic conditions by coculture of Clostridium acetobutylicum and Nesterenkonia sp. strain F. Biotechnol Bioeng. 117, 392-405. doi: 10.1002/bit.27221

Elia, N. M., Nokes, S. E., and Flythe, M. D. (2016). Switchgrass (Panicum virgatum) fermentation by Clostridium thermocellum and Clostridium saccharoperbutylacetonicum sequential culture in a continuous flow reactor. AIMS Energy 4:95. doi: 10.3934/energy.2016.1.95

Fang, H. H. P., Zhu, H., and Zhang, T. (2006). Phototrophic hydrogen production from glucose by pure and co-cultures of Clostridium butyricum and Rhodobacter sphaeroides. Int. J. Hydrogen Energy 31, 2223-2230. doi: 10.1016/j. ijhydene.2006.03.005

Flythe, M. D., Elía, N. M., Schmal, M. B., and Nokes, S. E. (2015). Switchgrass (panicum virgatum) fermentation by Clostridium thermocellum and Clostridium beijerinckii sequential culture: effect of feedstock particle size on gas production. Adv. Microbiol. 5, 311-316. doi: 10.4236/aim.2015.55031

Geng, A., He, Y., Qian, C., Xing, Y., and Zhou, Z. (2010). Effect of key factors on hydrogen production from cellulose in a co-culture of Clostridium thermocellum and Clostridium thermopalmarium. Bioresource Technol. 101, 4029-4033. doi: 10.1016/j.biortech.2010.01.042

Gomez-Flores, M., Nakhla, G., and Hafez, H. (2017). Hydrogen production and microbial kinetics of Clostridium termitidis in mono-culture and co-culture with Clostridium beijerinckii on cellulose. AMB Express 7:84. doi: 10.1186/ s13568-016-0256-2
Harish, K. R. Y., Srijana, M., Madhusudhan, R. D., and Gopal, R. (2010). Coculture fermentation of banana agro-waste to ethanol by cellulolytic thermophilic Clostridium thermocellum CT2. Afr. J. Biotechnol. 9, 1926-1934. doi: 10.5897/ AJB09.1217

Hitit, Z. Y., Lazaro, C. Z., and Hallenbeck, P. C. (2017a). Hydrogen production by co-cultures of Clostridium butyricum and Rhodospeudomonas palustris: optimization of yield using response surface methodology. Int. J. Hydrogen Energy 42, 6578-6589. doi: 10.1016/j.ijhydene.2016.12.122

Hitit, Z. Y., Lazaro, C. Z., and Hallenbeck, P. C. (2017b). Increased hydrogen yield and COD removal from starch/glucose based medium by sequential dark and photo-fermentation using Clostridium butyricum and Rhodopseudomonas palustris. Int. J. Hydrogen Energy 42, 18832-18843. doi: 10.1016/j.ijhydene.2017. 05.161

Hoang, V. T., Hoang, D. H., Pham, N. D., Tran, H. M., Bui, H. T. V., and Anh, T. N. (2018). Hydrogen production by newly isolated Clostridium species from cow rumen in pure-and co-cultures on a broad range of carbon sources. Aims Energy 6, 846-865. doi: 10.3934/energy.2018.5.846

Islam, M. S., Zhang, C., Sui, K.-Y., Guo, C., and Liu, C.-Z. (2017). Coproduction of hydrogen and volatile fatty acid via thermophilic fermentation of sweet sorghum stalk from co-culture of Clostridium thermocellum and Clostridium thermosaccharolyticum. Int. J. Hydrogen Energy 42, 830-837. doi: 10.1016/j. ijhydene.2016.09.117

Ivey, M., Massel, M., and Phister, T. G. (2013). Microbial interactions in food fermentations. Annu. Rev. Food Sci. Technol. 4, 141-162. doi: 10.1146/annurevfood-022811-101219

Jalil, N. K. A., Asli, U. A., Hashim, H., Jalil, A. A., Ahmad, A., and Khamis, A. K. (2018). Biohydrogen production from pineapple biomass residue using immobilized co-culture of Clostridium sporogenes and Enterobacter aerogenes. J. Energy. Saf. Technol. 1, 51-57. doi: 10.11113/jest.v1n1.8

Jiang, Y., Wu, R., Zhou, J., He, A., Xu, J., Xin, F., et al. (2019). Recent advances of biofuels and biochemicals production from sustainable resources using co-cultivation systems. Biotechnol Biofuels 12:155. doi: 10.1186/s13068-0191495-7

Jiao, Y., Navid, A., Stewart, B. J., Mckinlay, J. B., Thelen, M. P., and PettRidge, J. (2012). Syntrophic metabolism of a co-culture containing Clostridium cellulolyticum and Rhodopseudomonas palustris for hydrogen production. Int. J. Hydrogen Energy 37, 11719-11726. doi: 10.1016/j.ijhydene.2012. 05.100

Kao, P.-M., Hsu, B.-M., Chang, T.-Y., Chiu, Y.-C., Tsai, S.-H., Huang, Y.L., et al. (2016a). Biohydrogen production by Clostridium butyricum and Rhodopseudomonas palustris in co-cultures. Int. J. Green Energy 13, 715-719. doi: 10.1080/15435075.2015.1088443

Kao, P.-M., Hsu, B.-M., Huang, K.-H., Tao, C.-W., Chang, C.-M., and Ji, W.T. (2014). Biohydrogen production by immobilized co-culture of Clostridium butyricum and Rhodopseudomonas palustris. Energy Procedia 61, 834-837. doi: 10.1016/j.egypro.2014.11.976

Kao, P.-M., Hsu, B.-M., Tao, C.-W., Hsu, T.-K., and Chang, C.-M. (2016b). Control strategies for biohydrogen production by immobilized co-culture of Clostridium butyricum and Rhodopseudomonas palustris. Int. J. Green Energy 13, 977-982. doi: 10.1080/15435075.2015.1088444

Kim, H., Jeon, B. S., Pandey, A., and Sang, B.-I. (2018). New coculture system of Clostridium spp. and Megasphaera hexanoica using submerged hollow-fiber membrane bioreactors for caproic acid production. Bioresour. Technol. 270, 498-503. doi: 10.1016/j.biortech.2018.09.033

Kiyoshi, K., Furukawa, M., Seyama, T., Kadokura, T., Nakazato, A., and Nakayama, S. (2015). Butanol production from alkali-pretreated rice straw by co-culture of Clostridium thermocellum and Clostridium saccharoperbutylacetonicum. Bioresour. Technol. 186, 325-328. doi: 10.1016/j.biortech.2015. 03.061

Laurinavichene, T., Laurinavichius, K., Shastik, E., and Tsygankov, A. (2016). Inhibited growth of Clostridium butyricum in efficient H2-producing co-culture with Rhodobacter sphaeroides. Appl. Microbiol. Biotechnol. 100, 10649-10658. doi: 10.1007/s00253-016-7977-7

Laurinavichene, T., Laurinavichius, K., Shastik, E., and Tsygankov, A. (2018). Long-term H2 photoproduction from starch by co-culture of Clostridium butyricum and Rhodobacter sphaeroides in a repeated batch process. Biotechnol. Lett. 40, 309-314. doi: 10.1007/s10529-0172486-z 
Laurinavichene, T., and Tsygankov, A. (2015). Hydrogen photoproduction by coculture Clostridium butyricum and Rhodobacter sphaeroides. Int. J. Hydrogen Energy 40, 14116-14123. doi: 10.1016/j.ijhydene.2015.08.086

Laurinavichene, T., and Tsygankov, A. (2016). Different types of H2 photoproduction by starch-utilizing co-cultures of Clostridium butyricum and Rhodobacter sphaeroides. Int. J. Hydrogen Energy 41, 13419-13425. doi: 10.1016/j.ijhydene.2016.06.117

Laxman Pachapur, V., Jyoti Sarma, S., Kaur Brar, S., Le Bihan, Y., Ricardo Soccol, C., Buelna, G., et al. (2015). Co-culture strategies for increased biohydrogen production. Int. J. Energy Res. 39, 1479-1504. doi: 10.1002/er.3364

Lee, J.-Y., Chen, X.-J., Lee, E.-J., and Min, K.-S. (2012). Effects of pH and carbon sources on biohydrogen production by co-culture of Clostridium butyricum and Rhodobacter sphaeroides. J. Microbiol. Biotechnol. 22, 400-406. doi: 10.4014/ jmb.1108.08009

Li, Q., Guo, C., and Liu, C.-Z. (2014). Dynamic microwave-assisted alkali pretreatment of cornstalk to enhance hydrogen production via coculture fermentation of Clostridium thermocellum and Clostridium thermosaccharolyticum. Biomass Bioenergy 64, 220-229. doi: 10.1016/j. biombioe.2014.03.053

Li, Q., and Liu, C. Z. (2012). Co-culture of Clostridium thermocellum and Clostridium thermosaccharolyticum for enhancing hydrogen production via thermophilic fermentation of cornstalk waste. Int. J. Hydrogen Energy 37, 10648-10654. doi: 10.1016/j.ijhydene.2012.04.115

Li, X., and Henson, M. A. (2019). Metabolic modeling of bacterial co-culture systems predicts enhanced carbon monoxide-to-butyrate conversion compared to monoculture systems. Biochem. Eng. J. 151:107338. doi: 10.1016/j.bej.2019. 107338

Lin, Y. J., Wen, Z. Q., Zhu, L., Lin, J. P., and Cen, P. L. (2013). Butanol production from corncob in the sequential co-culture of Clostridium thermocellum and Clostridium beijerinckii. J. Chem. Eng. Chin. Univ. 27, 444-449. doi: 10.3969/ j.issn.1003-9015.2013.03.013

Liu, Y., Yu, P., Song, X., and Qu, Y. (2008). Hydrogen production from cellulose by co-culture of Clostridium thermocellum JN4 and Thermoanaerobacterium thermosaccharolyticum GD17. Int. J. Hydrogen Energy 33, 2927-2933. doi: 10. 1016/j.ijhydene.2008.04.004

López-Contreras, A. M., Smidt, H., Van Der Oost, J., Claassen, P. A., Mooibroek, H., and De Vos, W. M. (2001). Clostridium beijerinckii cells expressing Neocallimastix patriciarum glycoside hydrolases show enhanced lichenan utilization and solvent production. Appl. Environ. Microbiol. 67, 5127-5133. doi: 10.1128/AEM.67.11.5127-5133.2001

Lu, H., Chen, J., Jia, Y., Cai, M., and Lee, P. K. H. (2016). Transcriptomic responses of the interactions between Clostridium cellulovorans $743 \mathrm{~B}$ and Rhodopseudomonas palustris CGA009 in a cellulose-grown coculture for enhanced hydrogen production. Appl. Environ. Microbiol. 82, 4546-4559. doi: 10.1128/AEM.00789-16

Lu, H., and Lee, P. K. H. (2015). Effects of cellulose concentrations on the syntrophic interactions between Clostridium cellulovorans 743B and Rhodopseudomonas palustris CGA009 in coculture fermentation for biohydrogen production. Int. J. Hydrogen Energy 40, 11800-11808. doi: 10. 1016/j.ijhydene.2015.05.135

Lu, H., Ng, S. K., Jia, Y., Cai, M., and Lee, P. K. H. (2017). Physiological and molecular characterizations of the interactions in two cellulose-to-methane cocultures. Biotechnol. Biofuels 10:37. doi: 10.1186/s13068-017-0719-y

Luo, H., Ge, L., Zhang, J., Ding, J., Chen, R., and Shi, Z. (2016). Enhancing acetone biosynthesis and acetone-butanol-ethanol fermentation performance by coculturing Clostridium acetobutylicum/Saccharomyces cerevisiae integrated with exogenous acetate addition. Bioresour. Technol. 200, 111-120. doi: 10.1016/j. biortech.2015.09.116

Luo, H., Ge, L., Zhang, J., Zhao, Y., Ding, J., Li, Z., et al. (2015). Enhancing butanol production under the stress environments of co-culturing Clostridium acetobutylicum/Saccharomyces cerevisiae integrated with exogenous butyrate addition. PLoS One 10:e0141160. doi: 10.1371/journal.pone.0141160

Luo, H., Zeng, Q., Han, S., Wang, Z., Dong, Q., Bi, Y., et al. (2017). Highefficient n-butanol production by co-culturing Clostridium acetobutylicum and Saccharomyces cerevisiae integrated with butyrate fermentative supernatant addition. World J. Microbiol. Biotechnol. 33:76. doi: 10.1007/s11274-0172246-1
Mai, S., Wang, G., Wu, P., Gu, C., Liu, H., Zhang, J., et al. (2016). Interactions between Bacillus cereus CGMCC 1.895 and Clostridium beijerinckii NCIMB 8052 in co-culture for butanol production under non-anaerobic conditions. Biotechnol. Appl. Biochem. 64, 719-726. doi: 10.1002/bab.1522

Masset, J., Calusinska, M., Hamilton, C., Hiligsmann, S., Joris, B., Wilmotte, A., et al. (2012). Fermentative hydrogen production from glucose and starch using pure strains and artificial co-cultures of Clostridium spp. Biotechnol. Biofuels 5:35. doi: 10.1186/1754-6834-5-35

Mi, S., Gu, C., Wu, P., Liu, H., Yan, X., Li, D., et al. (2018). Improvement of butanol production by the development and co-culture of C. acetobutylicum TSH1 and B. cereus TSH2. Appl. Microbiol. Biotechnol. 102, 6753-6763. doi: 10.1007/s00253-018-9151-x

Mori, Y. (1990). Characterization of a symbiotic coculture of Clostridium thermohydrosulfuricum YM3 and Clostridium thermocellum YM4. Appl. Environ. Microbiol. 56, 37-42. doi: 10.1128/aem.56.1.37-42.1990

Morsy, F. M. (2017). Synergistic dark and photo-fermentation continuous system for hydrogen production from molasses by Clostridium acetobutylicum ATCC 824 and Rhodobacter capsulatus DSM 1710. J. Photochem. Photobiol. B. 169, 1-6. doi: 10.1016/j.jphotobiol.2017.02.011

Moscoviz, R., De Fouchécour, F., Santa-Catalina, G., Bernet, N., and Trably, E. (2017). Cooperative growth of Geobacter sulfurreducens and Clostridium pasteurianum with subsequent metabolic shift in glycerol fermentation. Sci. Rep. 7:44334. doi: 10.1038/srep44334

Nakayama, S., Bando, Y., Ohnishi, A., Kadokura, T., and Nakazato, A. (2013). Decreased hydrogen production leads to selective butanol production in co-cultures of Clostridium thermocellum and Clostridium saccharoperbutylacetonicum strain N1-4. J. Biosci. Bioeng. 115, 173-175. doi: 10.1016/j.jbiosc.2012.08.020

Nakayama, S., Kiyoshi, K., Kadokura, T., and Nakazato, A. (2011). Butanol production from crystalline cellulose by cocultured Clostridium thermocellum and Clostridium saccharoperbutylacetonicum N1-4. Appl. Environ. Microbiol. 77, 6470-6475. doi: 10.1128/AEM.00706-11

Nasr, N., Gupta, M., Hafez, H., El Naggar, M. H., and Nakhla, G. (2017). Monoand co-substrate utilization kinetics using mono-and co-culture of Clostridium beijerinckii and Clostridium saccharoperbutylacetonicum. Bioresour. Technol. 241, 152-160. doi: 10.1016/j.biortech.2017.05.086

Ndaba, B., Chiyanzu, I., and Marx, S. (2015). Direct fermentation of sweet sorghum juice by Clostridium acetobutylicum and Clostridium tetanomorphum to produce bio-butanol and organic acids. Biofuel. Res. J. 2, 248-252. doi: 10.18331/BRJ2015.2.2.7

Ng, T. K., Ben-Bassat, A., and Zeikus, J. G. (1981). Ethanol production by thermophilic bacteria: fermentation of cellulosic substrates by cocultures of Clostridium thermocellum and Clostridium thermohydrosulfuricum. Appl. Environ. Microbiol. 41, 1337. doi: 10.1128/aem.41.6.1337-1343.1981

Nishio, N., Kuroda, K., and Nagai, S. (1990). Methanogenesis of glucose by defined thermophilic coculture of Clostridium thermoaceticum and Methanosarcina sp. J. Ferment. Bioeng. 70, 398-403. doi: 10.1016/0922-338X(90)90121-C

Oliva-Rodríguez, A. G., Quintero, J., Medina-Morales, M. A., Morales-Martínez, T. K., Rodríguez-De la Garza, J. A., Moreno-Dávila, M., et al. (2019). Clostridium strain selection for co-culture with Bacillus subtilis for butanol production from agave hydrolysates. Bioresour. Technol. 275, 410-415. doi: 10.1016/j.biortech.2018.12.085

Pachapur, V. L., Das, R. K., Brar, S. K., Le Bihan, Y., and Buelna, G. (2016a). Valorization of crude glycerol and eggshell biowaste as media components for hydrogen production: a scale-up study using co-culture system. Bioresour. Technol. 225, 386-394. doi: 10.1016/j.biortech.2016.11.114

Pachapur, V. L., Sarma, S. J., Brar, S. K., Bihan, Y. L., Buelna, G., and Verma, M. (2017). Hydrogen production from biodiesel industry waste by using a co-culture of Enterobacter aerogenes and Clostridium butyricum. Biofuels 8, 651-662. doi: 10.1080/17597269.2015.112 2471

Pachapur, V. L., Sarma, S. J., Brar, S. K., Le Bihan, Y., Buelna, G., and Soccol, C. R. (2015a). Evidence of metabolic shift on hydrogen, ethanol and 1, 3propanediol production from crude glycerol by nitrogen sparging under microaerobic conditions using co-culture of Enterobacter aerogenes and Clostridium butyricum. Int. J. Hydrogen Energy 40, 8669-8676. doi: 10.1016/j.ijhydene.2015. 05.024 
Pachapur, V. L., Sarma, S. J., Brar, S. K., Le Bihan, Y., Buelna, G., and Verma, M. (2015b). Biohydrogen production by co-fermentation of crude glycerol and apple pomace hydrolysate using co-culture of Enterobacter aerogenes and Clostridium butyricum. Bioresour. Technol. 193, 297-306. doi: 10.1016/j. biortech.2015.06.095

Pachapur, V. L., Sarma, S. J., Brar, S. K., Le Bihan, Y., Buelna, G., and Verma, M. (2016b). Surfactant mediated enhanced glycerol uptake and hydrogen production from biodiesel waste using co-culture of Enterobacter aerogenes and Clostridium butyricum. Renew. Energy 95, 542-551. doi: 10.1016/j.renene.2016. 03.097

Pang, J., Hao, M., Li, Y., Liu, J., Lan, H., Zhang, Y., et al. (2018a). Consolidated bioprocessing using Clostridium thermocellum and Thermoanaerobacterium thermosaccharolyticum co-culture for enhancing ethanol production from corn straw. Bioresources 13, 8209-8221. doi: 10.15376/biores.13.4.8209-8221

Pang, J., Hao, M., Shi, Y., Li, Y., Zhu, M., Hu, J., et al. (2018b). Enhancing the ethanol yield from salix using a Clostridium thermocellum and Thermoanaerobacterium thermosaccharolyticum co-culture system. Bioresources 13, 5377-5393. doi: 10.3389/fmicb.2019.02035

Phowan, P., Reungsang, A., and Danvirutai, P. (2010). Bio-hydrogen production from cassava pulp hydrolysate using co-culture of Clostridium butyricum and Enterobacter aerogenes. Biotechnology 9, 348-354. doi: 10.3923/biotech.2010. 348.354

Qi, G., Xiong, L., Luo, M., Huang, Q., Huang, C., Li, H., et al. (2018). Solvents production from cassava by co-culture of Clostridium acetobutylicum and Saccharomyces cerevisiae. J. Environ. Chem. Eng. 6, 128-133. doi: 10.1016/j.jece. 2017.11.067

Qiang, H., Hemme, C. L., Helong, J., Zhili, H., and Jizhong, Z. (2011). Mechanisms of enhanced cellulosic bioethanol fermentation by co-cultivation of Clostridium and Thermoanaerobacter spp. Bioresour. Technol. 102, 9586-9592. doi: 10.1016/ j.biortech.2011.07.098

Qin, Y., Dong, Z., and Liu, L. (2009). Manipulation of NADH metabolism in industrial strains. Chin. J. Biotechnol. 25:161. doi: 10.1172/JCI102481

Rabemanolontsoa, H., Kuninori, Y., and Saka, S. (2016). High conversion efficiency of Japanese cedar hydrolyzates into acetic acid by co-culture of Clostridium thermoaceticum and Clostridium thermocellum. J. Chem. Technol. Biotechnol. 91, 1040-1047. doi: 10.1002/jctb.4679

Rabemanolontsoa, H., Van Nguyen, D., Jusakulvjit, P., and Saka, S. (2017). Effects of gas condition on acetic acid fermentation by Clostridium thermocellum and Moorella thermoacetica (C. thermoaceticum). Appl. Microbiol. Biotechnol. 101, 6841-6847. doi: 10.1007/s00253-017-8376-4

Raut, M. P., Pham, T. K., Gomez, L. D., Dimitriou, I., and Wright, P. C. (2019). Alcoholic fermentation of thermochemical and biological hydrolysates derived from miscanthus biomass by Clostridium acetobutylicum ATCC 824. Biomass Bioenergy 130:105382. doi: 10.1016/j.biombioe.2019.105382

Richter, H., Molitor, B., Diender, M., Sousa, D. Z., and Angenent, L. T. (2016). A narrow $\mathrm{pH}$ range supports butanol, hexanol, and octanol production from syngas in a continuous co-culture of Clostridium ljungdahlii and Clostridium kluyveriwith in-line product extraction. Front. Microbiol. 7:1733. doi: 10.3389/ fmicb. 2016.01773

Saddler, J., and Chan, M.-H. (1984). Conversion of pretreated lignocellulosic substrates to ethanol by Clostridium thermocellum in mono-and co-culture with Clostridium thermosaccharolyticum and Clostridium thermohydrosulphuricum. Can. J. Microbiol. 30, 212-220. doi: 10.1139/m84-032

Salimi, F., and Mahadevan, R. (2013). Characterizing metabolic interactions in a clostridial co-culture for consolidated bioprocessing. BMC Biotechnol. 13:95. doi: 10.1186/1472-6750-13-95

Salimi, F., Zhuang, K., and Mahadevcm, R. (2010). Genome-scale metabolic modeling of a clostridial co-culture for consolidated bioprocessing. Biotechnol. J. 5, 726-738. doi: 10.1002/biot.201000159

Sander, K., Asano, K. G., Bhandari, D., Van Berkel, G. J., Brown, S. D., Davison, B., et al. (2017). Targeted redox and energy cofactor metabolomics in Clostridium thermocellum and Thermoanaerobacterium saccharolyticum. Biotechnol. Biofuels 10:270. doi: 10.1186/s13068-017-0960-4

Santilal, M. (2015). Fermentative hydrogen production from molasses using pure, and co-cultures of Clostridium butyricum, and Clostridium beijerinckii by batch study. Reinvention Int. J. Undergraduate Res. 8. Available online at: http://www. warwick.ac.uk/reinventionjournal/archive/volume8issue2/santilal
Sasaki, D., Morita, M., Sasaki, K., Watanabe, A., and Ohmura, N. (2012). Acceleration of cellulose degradation and shift of product via methanogenic co-culture of a cellulolytic bacterium with a hydrogenotrophic methanogen. J. Biosci. Bioeng. 114, 435-439. doi: 10.1016/j.jbiosc.2012.05.002

Sato, K., Goto, S., Yonemura, S., Sekine, K., and Saiki, T. (1992). Effect of yeast extract and vitamin B12 on ethanol production from cellulose by Clostridium thermocellum I-1-B. Appl. Environ. Microbiol. 58, 734-736. doi: 10.1128/AEM. 58.2.734-736.1992

Seppälä, J. J., Puhakka, J. A., Yli-Harja, O., Karp, M. T., and Santala, V. (2011). Fermentative hydrogen production by Clostridium butyricum and Escherichia coli in pure and cocultures. Int. J. Hydrogen Energy 36, 10701-10708. doi: 10.1016/j.ijhydene.2011.05.189

Srivastava, N., Srivastava, M., Gupta, V. K., Ramteke, P., and Mishra, P. (2018). A novel strategy to enhance biohydrogen production using graphene oxide treated thermostable crude cellulase and sugarcane bagasse hydrolyzate under co-culture system. Bioresource Technol. 270, 337-345. doi: 10.1016/j.biortech. 2018.09.038

Sun, Q., Xiao, W., Dan, X. I., Shi, J., Yan, X., and Zhou, Z. (2010). Statistical optimization of biohydrogen production from sucrose by a co-culture of Clostridium acidisoli and Rhodobacter sphaeroides. Int. J. Hydrogen Energy 35, 4076-4084. doi: 10.1016/j.ijhydene.2010.01.145

Takagi, D., Okamura, S., Tanaka, K., Ikenaga, N., Iwashima, M., Haghparast, S. M. A., et al. (2016). Characterization of hydrogen production by the co-culture of dark-fermentative and photosynthetic bacteria. Res. Chem. Intermediat. 42, 7713-7722. doi: 10.1007/s11164-016-2656-y

Tang, I.-C., Yang, S.-T., and Okos, M. R. (1988). Acetic acid production from whey lactose by the co-culture of Streptococcus lactis and Clostridium formicoaceticum. Appl. Microbiol. Biotechnol. 28, 138-143. doi: 10.1007/ BF00694301

Tavabe, F. R., Saadat, S., and Talebbeydokhti, N. (2010). Bio-hydrogen Production from Food Waste by a Co-Culture of Clostridium acetobutylicum and Rhodobacter sphaeroides. Shiraz: Shiraz University.

Tomita, H., Okazaki, F., and Tamaru, Y. (2019). Direct IBE fermentation from mandarin orange wastes by combination of Clostridium cellulovorans and Clostridium beijerinckii. AMB Expr. 9:1. doi: 10.1186/s13568-018-0728-7

Tran, H. T. M., Cheirsilp, B., Hodgson, B., and Umsakul, K. (2010). Potential use of Bacillus subtilis in a co-culture with Clostridium butylicum for acetonebutanol-ethanol production from cassava starch. Biochem. Eng. J. 48, 260-267. doi: 10.1016/j.bej.2009.11.001

Tran, H. T. M., Cheirsilp, B., Umsakul, K., and Bourtoom, T. (2011). Response surface optimisation for acetone-butanol-ethanol production from cassava starch by co-culture of Clostridium butylicum and Bacillus subtilis. Maejo Int. J. Sci. Technol. 5, 374-389.

Valdez-Vazquez, I., Castillo-Rubio, L. G., Pérez-Rangel, M., Sepúlveda-Gálvez, A., and Vargas, A. (2019). Enhanced hydrogen production from lignocellulosic substrates via bioaugmentation with Clostridium strains. Ind. Crop. Prod. 137, 105-111. doi: 10.1016/j.indcrop.2019.05.023

Wang, A., Ren, N., Shi, Y., and Lee, D.-J. (2008). Bioaugmented hydrogen production from microcrystalline cellulose using co-culture-Clostridium acetobutylicum X9 and Ethanoigenens harbinense B49. Int. J. Hydrogen Energy 33, 912-917. doi: 10.1016/j.ijhydene.2007.10.017

Wang, F., Wang, M., Zhao, Q., Niu, K., Liu, S., He, D., et al. (2019). Exploring the relationship between Clostridium thermocellum JN4 and Thermoanaerobacterium thermosaccharolyticum GD17. Front. Microbiol. 10:2035.

Wang, M., Zhao, Q., Li, L., Niu, K., Li, Y., Wang, F., et al. (2016). Contributing factors in the improvement of cellulosic $\mathrm{H} 2$ production in Clostridium thermocellum/Thermoanaerobacterium co-cultures. Appl. Microbiol. Biotechnol. 100, 8607-8620. doi: 10.1007/s00253-016-7776-1

Wang, Z., Cao, G., Zheng, J., Fu, D., Song, J., Zhang, J., et al. (2015). Developing a mesophilic co-culture for direct conversion of cellulose to butanol in consolidated bioprocess. Biotechnol. Biofuels 8:84. doi: 10.1186/s13068-0150266-3

Wen, Z., Wu, M., Lin, Y., Yang, L., Lin, J., and Cen, P. (2014a). A novel strategy for sequential co-culture of Clostridium thermocellum and Clostridium beijerinckii to produce solvents from alkali extracted corn cobs. Process. Biochem. 49, 1941-1949. doi: 10.1016/j.procbio.2014.07.009 
Wen, Z., Wu, M., Lin, Y., Yang, L., Lin, J., and Cen, P. (2014b). Artificial symbiosis for acetone-butanol-ethanol (ABE) fermentation from alkali extracted deshelled corn cobs by co-culture of Clostridium beijerinckii and Clostridium cellulovorans. Microb. Cell Fact. 13:92. doi: 10.1186/s12934-0140092-5

Wu, J., Dong, L., Zhou, C., Liu, B., Feng, L., Wu, C., et al. (2019). Developing a coculture for enhanced butanol production by Clostridium beijerinckii and Saccharomyces cerevisiae. Bioresour. Technol. Rep. 6, 223-228. doi: 10.1016/j. biteb.2019.03.006

Wu, P., Wang, G., Wang, G., Børresen, B. T., Liu, H., and Zhang, J. (2016). Butanol production under microaerobic conditions with a symbiotic system of Clostridium acetobutylicum and Bacillus cereus. Microb. Cell Fact. 83, 1193 1199. doi: 10.1186/s12934-016-0412-z

Wushke, S., Levin, D., Cicek, N., and Sparling, R. (2015). Characterization of the facultative anaerobe Caldibacillus debilis GB1 and its use in a designed aerotolerant, cellulose degrading, co-culture with Clostridium thermocellum. Appl. Environ. Microbiol. 81, 5567-5573. doi: 10.1128/AEM.00735-15

Xia, D., Alexander, A. K., Isbell, A., Zhang, S., Ou, J., and Liu, X. M. (2017). Establishing a co-culture system for Clostridium cellulovorans and Clostridium aceticum for high efficiency biomass transformation. J. Sci. Heal. Univ. Ala. 14, 8-13.

$\mathrm{Xu}, \mathrm{L}$. , and Tschirner, U. (2011). Improved ethanol production from various carbohydrates through anaerobic thermophilic co-culture. Bioresour. Technol. 102, 10065-10071. doi: 10.1016/j.biortech.2011.08.067

$\mathrm{Xu}, \mathrm{L}$., and Tschirner, U. (2014). Immobilized anaerobic fermentation for bio-fuel production by Clostridium co-culture. Bioprocess. Biosyst. Eng. 37, 1551-1559. doi: 10.1007/s00449-014-1127-3

Yagi, O. (2011). Biodegradation of halogenated organic compounds. J. Jpn. Soc. Water Environ. 8, 289-295. doi: 10.2965/jswe1978.8.289

Yan, S., and Dong, D. (2018). Improvement of caproic acid production in a Clostridium kluyveri H068 and Methanogen 166 co-culture fermentation system. AMB Expr. 8:175. doi: 10.1186/s13568-018-0705-1

Ye, X., Morgenroth, E., Zhang, X., and Finneran, K. T. (2011). Anthrahydroquinone-2,6,-disulfonate (AH2QDS) increases hydrogen molar yield and xylose utilization in growing cultures ofClostridium beijerinckii. Appl. Microbiol. Biotechnol. 92, 855-864. doi: 10.1007/s00253-011-3571-1

Youn, G. S. (2017). Bioethanol and Biobutanol Production with Clostridium carboxidivorans, Clostridium beijerinckii, and Co-Culture from Biomass: Carbon Dioxide/Hydrogen Gas vs. Glucose Fermentation. Columbus, OH: The Ohio State University.

Yu, E., Chan, M.-H., and Saddler, J. (1985). Butanol production from cellulosic substrates by sequential co-culture of Clostridiumthermocellum and C. acetobutylicum. Biotechnol. Lett. 7, 509-514. doi: 10.1007/BF0119 9870

Zagrodnik, R., and Laniecki, M. (2015). The role of pH control on biohydrogen production by single stage hybrid dark- and photo-fermentation. Bioresour. Technol. 194, 187-195. doi: 10.1016/j.biortech.2015.07.028

Zagrodnik, R., and Łaniecki, M. (2017a). The effect of pH on cooperation between dark-and photo-fermentative bacteria in a co-culture process for hydrogen production from starch. Int. J. Hydrogen Energy 42, 2878-2888. doi: 10.1016/ j.ijhydene.2016.12.150
Zagrodnik, R., and Łaniecki, M. (2017b). Hydrogen production from starch by coculture of Clostridium acetobutylicum and Rhodobacter sphaeroides in one step hybrid dark-and photofermentation in repeated fed-batch reactor. Bioresour. Technol. 224, 298-306. doi: 10.1016/j.biortech.2016.10.060

Zhang, S., Qu, C., Huang, X., Suo, Y., Liao, Z., and Wang, J. (2016a). Enhanced isopropanol and $n$-butanol production by supplying exogenous acetic acid via co-culturing two Clostridium strains from cassava bagasse hydrolysate. J. Ind. Microbiol. Biotechnol. 43, 915-925. doi: 10.1007/s10295-016-1775-1

Zhang, S.-C., Lai, Q.-H., Lu, Y., Liu, Z.-D., Wang, T.-M., Zhang, C., et al. (2016b). Enhanced biohydrogen production from corn stover by the combination of Clostridium cellulolyticum and hydrogen fermentation bacteria. J. Biosci. Bioeng. 122, 482-487. doi: 10.1016/j.jbiosc.2016. 03.014

Zhang, X. (2013). Enhanced Biohydrogen Production and Substrate Utilization by Co-Culture Fermentation with Reduced Extracellular Electron Shuttles. Ph.D. thesis, The University of Illinois, Champaign, IL.

Zhang, X., Xiaofeng, Y., Finneran, K. T., Zilles, J. L., and Eberhard, M. (2012). Interactions between Clostridium beijerinckii and Geobacter metallireducens in co-culture fermentation with anthrahydroquinone-2, 6-disulfonate (AH2QDS) for enhanced biohydrogen production from xylose. Biotechnol. Bioeng. 110, 164-172. doi: 10.1002/bit.24627

Zhang, X., Ye, X., Guo, B., Finneran, K. T., Zilles, J. L., and Morgenroth, E. (2013). Lignocellulosic hydrolysates and extracellular electron shuttles for $\mathrm{H} 2$ production using co-culture fermentation with Clostridium beijerinckii and Geobacter metallireducens. Bioresour. Technol. 147, 89-95. doi: 10.1016/j. biortech.2013.07.106

Zhu, H., Wakayama, T., Asada, Y., and Miyake, J. (2001). Hydrogen production by four cultures with participation by anoxygenic phototrophic bacterium and anaerobic bacterium in the presence of NH4+. Int. J. Hydrogen Energy 26, 1149-1154. doi: 10.1016/s0360-3199(01)00038-6

Zou, W., Ye, G., Zhang, J., Zhao, C., Zhao, X., and Zhang, K. (2018a). Genomescale metabolic reconstruction and analysis for Clostridium kluyveri. Genome 61, 605-613. doi: 10.1139/gen-2017-0177

Zou, W., Ye, G., and Zhang, K. (2018b). Diversity, function, and application of Clostridium in Chinese strong flavor Baijiu ecosystem: a review. J. Food. Sci. 83, 193-1199. doi: 10.1111/1750-3841.14134

Zuroff, T. R., Xiques, S. B., and Curtis, W. R. (2013). Consortiamediated bioprocessing of cellulose to ethanol with a symbiotic Clostridium phytofermentans/yeast co-culture. Biotechnol. Biofuels 6:59. doi: 10.1186/1754-6834-6-59

Conflict of Interest: The authors declare that the research was conducted in the absence of any commercial or financial relationships that could be construed as a potential conflict of interest.

Copyright (c) $2020 \mathrm{Du}, \mathrm{Zou}$, Zhang, Ye and Yang. This is an open-access article distributed under the terms of the Creative Commons Attribution License (CC BY). The use, distribution or reproduction in other forums is permitted, provided the original author(s) and the copyright owner(s) are credited and that the original publication in this journal is cited, in accordance with accepted academic practice. No use, distribution or reproduction is permitted which does not comply with these terms. 